Portland State University

PDXScholar

$1-1-1982$

\title{
The measurement of economic diversification with reference to regional unemployment
}

Adil H. El-Haimus

Portland State University

Follow this and additional works at: https://pdxscholar.library.pdx.edu/open_access_etds Let us know how access to this document benefits you.

\section{Recommended Citation}

El-Haimus, Adil H., "The measurement of economic diversification with reference to regional unemployment" (1982). Dissertations and Theses. Paper 477.

https://doi.org/10.15760/etd.477

This Dissertation is brought to you for free and open access. It has been accepted for inclusion in Dissertations and Theses by an authorized administrator of PDXScholar. Please contact us if we can make this document more accessible: pdxscholar@pdx.edu. 
THE MEASUREMENT OF ECONOMIC DIVERSIFICATION WITH

REFERENCE TO REGIONAL UNEMPLOYMENT

by

ADIL H. EL-HAIMUS

A dissertation submitted in partial fulfillment of the requirements for the degree of

DOCTOR OF PHILOSOPHY

IN

URBAN STUDIES

Portland State University

1982 
TO THE OFFICE OF GRADUATE STUDIES AND RESEARCH:

The members of the Committee approve the dissertation of Adil H. E1-Haimus presented December 8, 1981.
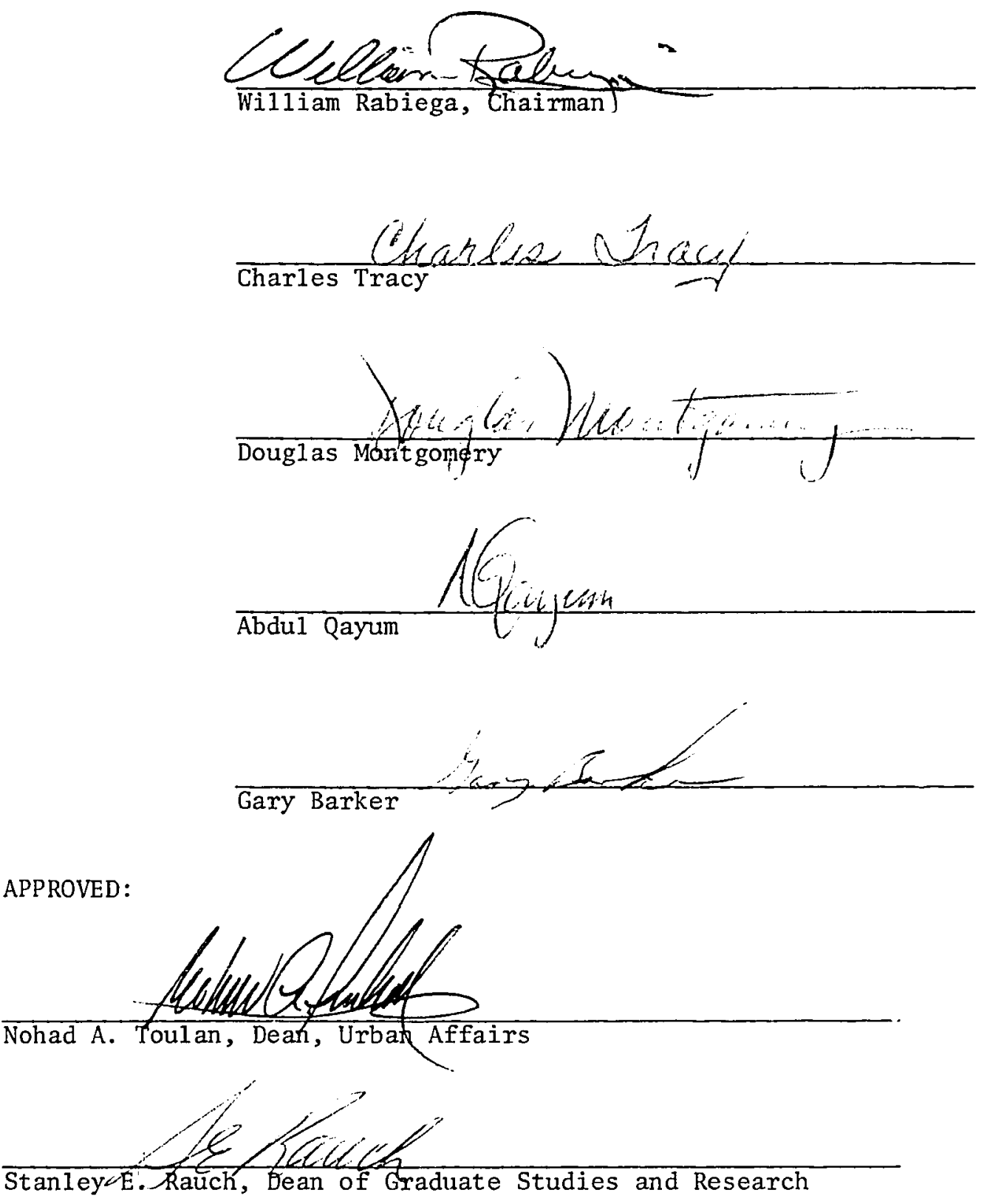
AN ABSTRACT OF THE DISSERTATION OF Adil H. E1-Haimus for the Doctor of Philosophy in Urban Studies presented December 8, 1981.

Title: The Measurement of Economic Diversification with Reference to Regional Unemployment.

APPROVED BY MEMBERS OF THE DISSERTATION COMMITTEE:
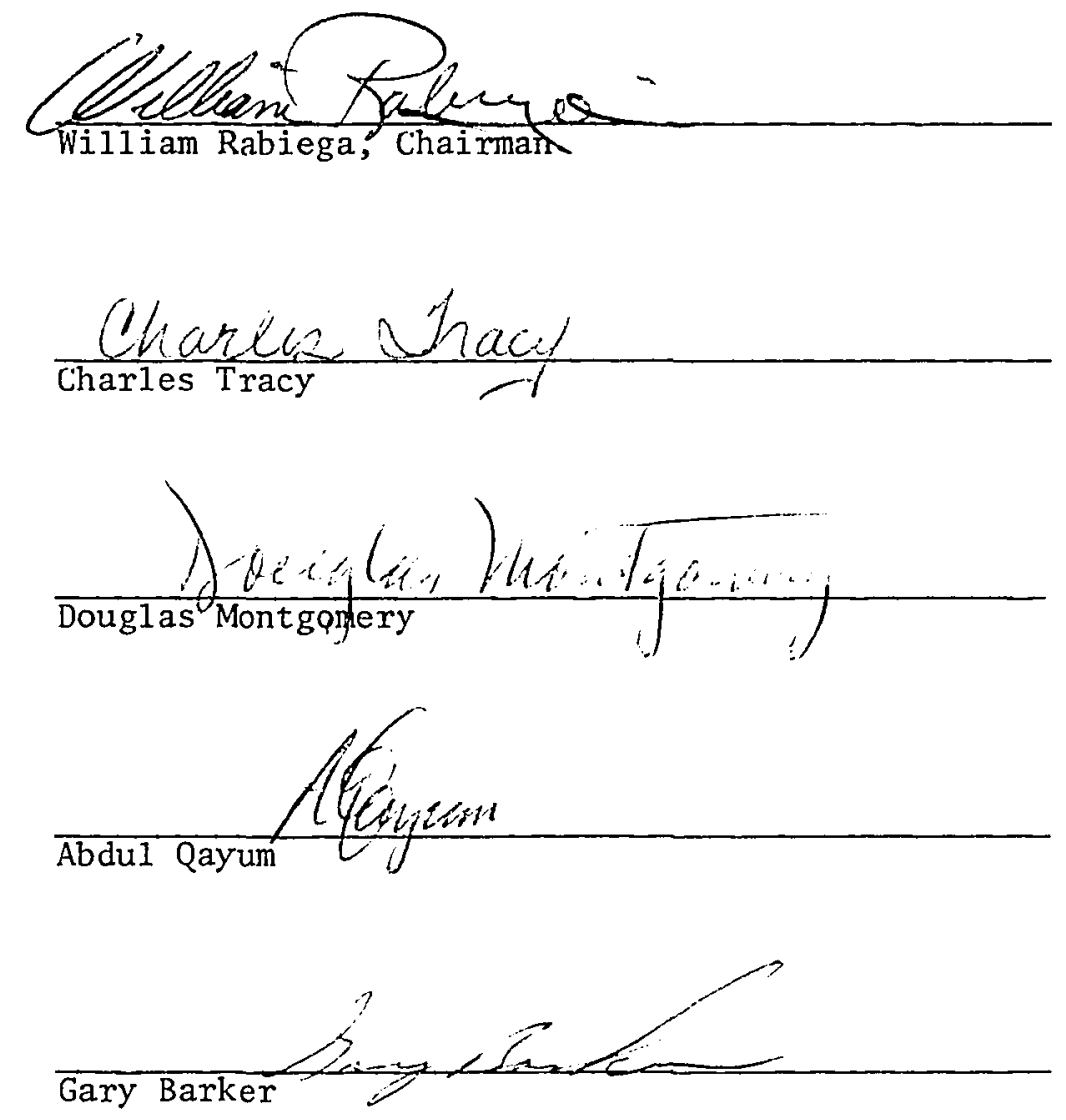

Over the past four years, considerable attention has been focused on the problems of high unemployment in the State of Oregon. 
The percentage of jobless continued to be higher than that of the nation. The depressed housing market, caused by high interest rates, coupled with an increase in the import of Canadian timber managed to reduce the demand for Oregon lumber and wood products drastically. This has resulted in an abnormally high unemployment rate in many of Oregon's counties which are dependent on the wood industry; for example, the 1980 jobless rate in Harney County reached a record high of 29 percent. On the other side of the spectrum, less dependent counties such as Gilliam and Morrow continued to grow during the same period, with unemployment rates of merely 4.9 and 5.8 percent respectively. These rates are approximately half the state average.

Community leaders, including the Governor, seem convinced that the only solution is economic diversification. It is an argument that makes a great deal of sense at first glance. The notion here is that if you diversify you will become less vulnerable to outside forces and hence will have a more stable economy. But what is diversification? How can we tell that one region is more diversified than another? Furthermore, having a diversified economy, does this ensure a lower rate of unemployment.

The thrust of this dissertation deals with providing answers to these questions. Three schools of thought - ogive-norm, portfolio variance and entropy - were examined in an effort to determine a more proper measure of economic diversification. Various statistical procedures of hypothesis testing were employed together with stepwise regression and analysis of variance. The research findings indicate that there is a definite relationship between economic diversification 
and regional unemployment. However, only 28 percent of the change in the rate of unemployment is explainable by changes in the levels of diversification. (The necessary data were provided by the State of Oregon - Employment Division). 
TABLE OF CONTENTS

PAGE

LIST OF TABLES . . . . . . . . . . . . . . . . . . . . . . . . . . . . . . v vi
LIST OF FIGURES
CHAPTER

I INTRODUCTION . . . . . . . . . . . . . . 1

II REVIEW OF LITERATURE . . . . . . . . . . . .

Definitions ............... 5

Ogive-Norm Approach . . . . . . . . . . 6

Portfolio Variance Approach . . . . . . . 12

Entropy Approach . . . . . . . . . . . 17

III STUDY DESIGN . . . . . . . . . . . . . . .

Level of Industrial Dependence (L.I.D.) . . . . 21

Data Sets ............... 27

Formulation of Other Measures of Diversification . 29

Hypothesis Testing . . . . . . . . . . 33

IV APTNESS OF DIVERSIFICATION MEASURES . . . . . . 36

$V$ THE RELATIONSHIP OF ECONOMIC DIVERSIFICATION TO

UNEMPLOYMENT RATE . . . . . . . . . . . . . 48 48

VI CONCLUSIONS AND RECOMMENDATIONS . . . . . . . .

Summary .. . . . . . . . . . . . 56

Conclusions . . . . . . . . . . . . 58

Recommendations ........... . . 59 
TABLE OF CONTENTS Continued

PAGE

A SELECTED BIBLIOGRAPHY . . . . . . . . . . . . 61 APPENDIX A

EXHIBIT 1 Florence Measure as Independent Variable . . . 69

EXHIBIT 2 Ogive Measure as Independent Variable . . . 70

EXHIBIT 3 Conroy Measure as Independent Variable . . . 71

EXHIBIT 4 L.I.D. as Independent Variable . . . . . 72

APPENDIX B

EXHIBIT 5 Morrow County Regression . . . . . . . . 75

EXHIBIT 6 Harney County Regression and Durbin-Watson Test for Harney and Morrow . . . . . . 76

APPENDIX C COEFFICIENTS OF CORRELATION AND PERCENT UNEMPLOYMENT, 1980

MATRIX 1 HARNEY COUNTY .............. 79

MATRIX 2 CROOK COUNTY . . . . . . . . . . . 80

MATRIX $3 \quad$ GRANT COUNTY . . . . . . . . . . . . . 81

MATRIX $4 \quad$ COOS COUNTY .............. 82

MATRIX 5 UMATILLA COUNTY . . . . . . . . . . 83

MATRIX 6 BENTON COUNTY ................ . . 84

MATRIX 7 MORROW COUNTY . . . . . . . . . . . 85

MATRIX $8 \quad$ GILLIAM COUNTY . . . . . . . . . . . 86 


\section{LIST OF TABLES}

TABLE

PAGE

I Regression Results Cross-Sectional Study . . . . . . 36

II Regression Results Longitudinal Study . . . . . . . 37

III Values of Diversification Measures and Unemployment Rates by County ............... 46

IV Percent Unemployment L.I.D. and Coefficients of Correlation for Selected Counties, 1980 . . . . . 50

V Multiple Linear Regression Results . . . . . . . . . 54 


\section{LIST OF FIGURES}

\section{FIGURE}

PAGE

1. Graphic Presentation of the Ogive Measure . . . . . . 10

2. County Map of the State of Oregon . . . . . . . . . 32

3. Residuals plot ................ 41

4. Unemployment Rates, Morrow and Harney Counties,

$$
1975 \text { to } 1976 \text {..................... } 42
$$

5. Unemployment Rates, Morrow and Harney Counties,

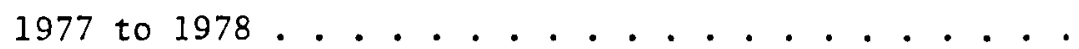

6. Unemployment Rates, Morrow and Harney Counties, 1979 to $1980 \ldots \ldots$ 
CHAPTER I

INTRODUCTION

On November 30, 1980, The Oregonian carried the following front page headline:

\section{Economic Opposites}

Morrow 'Booming' as Harney 'Busts'

In the text, Stan Federman of The Oregonian staff highlights this polarity among Oregon counties by pointing out the astonishing differences in their unemployment rates. Morrow is booming with a 4.4 percent rate of unemployment (half the state average) for the month of October while Harney is busting with a high rate of 29.9 percent. The picture for Harney was even worse during July when unemployment soared to 32.6 percent, the highest unemployment rate ever recorded for an Oregon county. The reasons for the huge difference in unemployment rates between the two counties is, according to Mr. Federman, very clear.

The Morrow and Harney econonic stories are prime examples of what happens when a county aggressively pursues a diversified economy - and what happens when another county does not $(9, p .1)$.

Speaking to members of the Eugene-Springfield Lhamber of Commerce on February 5, 1981, Governor Atiyeh of Oregon stressed the plight of their region by pointing out that

... we have seen how vulnerable our local economies are to the forces of national economic trends. Especially in the lumber and wood products industry, Oregon and Lane county were hard hit. Statewide, unemployment in this 
sector alone reached a high point of 17,000 early in the year. . . As the economy becomes less dependent on resource-based industries, the peaks and troughs in Oregon's employment, due to the business cycle becomes less pronounced. . . Every effort we make toward our own diversification moves us that much closer to our economic survival in the coming deca te $(1, \mathrm{pp}, 1-5)$.

The Governor also observed that accepting any new manufacturing firm in the interests of diversification might lead to degradation of the environment.

The desire to diversify is not limited to Oregon, but has received a nationwide policy and academic attention for some time. Conroy (1975) points out that

... as of 1971 there were no fewer than 4,513 different organizations actively involved in industrial development, the vast majority of them seeking to attract new or expanded industry to specific, very limited geographic areas $(7, p . x i i)$.

He further pointed out that forty-two of the fifty states provided revenue bonds for the purpose of financing new industries; state and local financing of such activities amounted to $\$ 4.9$ billion in 1971 . More recently (up to and including 1979) this figure has risen to approximately $\$ 24$ billion. From 1975 to 1980, the State of Oregon alone approved $\$ 245$ million of industrial (economic) development revenue bonds, and actually issued $\$ 90$ million.

While many seem to accept the idea that economic diversification is a good thing, some continue to disagree as to its merits. Manufacturing industries, as indicated earlier, have been encouraged to expand and locate new plants as part of the diversification scheme on the faith that they will reduce unemployment and stabilize the local economies. Yet a recent nationwide study by Richard Rosen (1980) of the Bureau of Labor Statistics points out that: 
An analysis of employment and unemployment changes during the 1974-75 recession confirms that states and areas with heavy concentrations of manufacturing employment were more likely to have higher jobless rates $(17$, p. 20).

Does a well-diversified economy insure a lower rate of unemployment?

Is an economy more diversified when it has a greater number of sectors or is it better to have employment more evenly distributed among fewer sectors? Presently, there is no clear consensus as to what constitutes a well-diversified economy.

In the academic literature, the subject of diversification has long been a point of discussion. Mclaughlin (1930) can perhaps be credited for the earliest comprehensive treatment of this subject. Since then, a score of other regional scientists have sought to define this phenomenon, to measure it, and to evaluate its impact on regional economies. Their efforts can be categorized into three methods or approaches: the ogive-norm, the portfolio analysis, and entropy.

The works of McLaughlin (1930), Tress (1938), Sykes (1950), Rodgers (1957), U1lman and Dacey (1960), Conkling (1963), Shear (1965), Parr (1965), Bahl, Firestine and Phares (1971), and Gratton (1979) are representative of the ogive-norm approach. Their method basically compares diversification of a region to a desired norm, such as that of the nation, or to an evenly distributed employment pattern.

The portfolio approach is found in the works of Conroy (1975), Barth, Kraft and Wiest (1975), and, to some degree, Larry St. Louis (1980). The thrust of this argument is that regional investment of resource into industries, can be compared to the process of choosing the right portfolio of stocks for a given investor. The right combina- 
tion, i.e. diversification, will produce the greatest returns. Their efforts were largely based on the previous work of Markowitz (1952), Tobin (1958) and Sharpe (1970) in the area of financial asset selection. Hackbart and Anderson (1975) attempted, with limited success, to use the entropy function as their measure of economic diversification. Their assumptions and results greatly resemble those of the ogive method. Unfortunately, none of these three approaches seem to provide an adequate measure of economic diversification.

This research is intended to determine the effect of economic diversification on regional unemployment. Particular emphasis will be placed initially on the development of a new and more appropriate measure of economic diversification. Subsequently, the following main hypothesis will be tested:

There is no relationship between the level of economic diversification and the rate of unemployment.

This research effort is not a treatise on the causes of regional unemployment, but rather an attempt to answer an equally important question, the policy of diversifying industry to lower unemployment. If a policy of economic diversification via revenue bonds or some other means is instituted - does this insure a lower rate of unemployment; in other words, is there a strong relationship (statistical association) between economic diversification and regional unemployment? 


\section{CHAPTER II}

\section{REVIEW OF PREVIOUS RESEARCH}

The primary objectives of this research effort, as stated earlier, are twofold: First, to develop a more appropriate measure of economic diversification, and second, is to test the hypothesis that there is no relationship between the level of diversification and the rate of unemployment. To pursue these tasks, the concept of economic diversification must be defined and past research efforts in this area must be critically reviewed.

\section{Definition}

Crowley (1973) defined industrial specialization first as being "The extent to which the labor force is concentrated in a small number of industry groupings," while diversification "refers to the extent to which it is dispersed over the same groupings" (8, p. 92). The same view was reflected earlier by Parr (1965) when he defined diversification "as the extent to which the economic activity of a region is distributed among a number of caiegories" (15, p. 22). Taylor (1967) on the other hand, introduces the notion of a "fully" diversified region. According to Taylor, "a region is fully diversified when the structure of industry is identical to the national pattern . . each industry would employ the same proportion of total employees in the region as in the national economy." Adding that "the current national pattern of industry, for instance, may not. be the most desirable one to impose 
upon a region" (23, p. 106). Hence, time can also be a factor to be reckoned with when we define "full" or "best" level of diversification. Conroy's (1974) portfolio approach observes diversification from yet another perspective, that of optimality. "Industrial diversification in the context of portfolio refers to the explicit attempt to reduce fluctuations or instability in aggregate returns to the region from its portfolio of returns-producing assets" (7, p. 32). The optimal portfolio, according to him, is that set of industries that yield the greatest trade-off between expected return and the variance of the distribution of the entire portfolio. Optimal portfolio, therefore, is not only concerned with maximum return, but with inter-industry relationships that can result in optimal sectorial structure. In the following section, various measures of diversification that have been developed over the past fifty years will be evaluated. The first of such measures can be grouped and identified as the ogive-norm.

Ogive-Norm

The ogive is a graphic method of representing economic diversification. Taking the diagonal of a rectangle to be a level of "absolute diversification," other patterns of diversification can then be plotted using cumulative percentages of employment. The diagonal, incidentally, is divided into ( $N$ ) equidistant points where $N$ is the number of industries in a given region. Other methods in this class may consider the national employment pattern as the desired norm, while others still may consider an average of, say, a set of SMSA's. In these cases, the percent distribution of employment among the various sectors of a given region is compared to that of the nation or to an average of all 
distributions of selected groups of SMSA's.

The objective of McLaughlin's (1930) research effort was to show "that there may be significant relations between the degress of industrial concentration in a given city and the business fluctuations which that city experiences" (14, p. 131). Concentration was taken to mean the opposite of diversification. This concern, as McLaughlin points out, was largely triggered by the fact that "in recent years there has been a great desire on the part of many cities to diversify their industrial activities with the belief that variations in production and employment would be less severe." (14, p. 131).

McLaughlin chose as a measure of concentration the percentage of each city's total manufacturing as accounted for by the fourteen largest industries. The lower the total percentage, the closer the city is to the ideal norm. His choice of a measure of concentration seems arbitrary, as do his methods of "gauging" the economic importance of an industry. He chose the value added by a manufacturer as the gauge rather than, say, the number of wage earners, capitalization, or value of product. He claimed "some inadequacy was found with each of these, taken by itself except with the value added by manufacture" (14, p. 134). By examining the 1919 Census of Manufacture, one can see that his choice was likely to have followed the Census' own evaluation of the value added. The Census stated that "for many purposes, therefore, the best measure of the importance of an industry, from manufacturing standpoint, is the value created by the manufacturing operations carried on with the industry" $(27, p .7)$. This value is calculated by deducting the cost of the materials used from the value of the product. The 
resulting figure is termed in the Census reports as value added by manufacture. In fact, value added is a poor variable to choose when one is to explain the impact of concentration (or diversification) on a given city. Would it not have been more meaningful to show the impact on the number of wage eamers? Value added, as stated above, is the best measure of the importance of an industry from a manufacturing point of view. How big a mark-up a manufacturer can place on an item is of less immediate impact on the economic welfare of a city than a change in the number of wage earners. Value added is an indicator of the level of profit which may or may not remain in the community to stimulate future jobs or maintain current level of employment. The fact that, for example, Detroit is more concentrated than Boston is of no significance unless we are shown how this can affect business fluctuations in a given community. Unfortunately, McLaughlin did not clearly illustrate this. Equally unclear is his method of determining what is a consumer good and what is a producer good. His main hypothesis in this case was that "value added in producers' goods is much more likely to show fluctuations than value added in consumers' goods" (14, p. 146). A car, for example, could be both a consumer and a producer good at the same time. "Thus motor vehicles were divided two-third consumer's goods, one-third producer good" (14, p. 149). The total percentages of all producer goods and all consumer goods (for the sixteen cities) were found to have a rank correlation of .88 and .93 with cyclical decrease in value added, respectively. One cannot but wonder as to what happens to these results if cars were to be considered half consumer goods and half producer goods. 
Putting things in perspective, this research was pursued more than fifty years ago. Perhaps Mr. McLaughlin's major accomplishment is in the questions he raised rather than the answers he provided. To put it into his words, these results do not warrant unqualified generalizations. . . but they give food for thought. Judging by the amount of literature that his work has triggered since, he most certainly succeeded in giving food for thought.

Several years later, Tress' (1938) main objective was to develop a more formal measure of diversification. His approach was basically to rank industries in the order of their percentage of the total industrial working population. These percentages were then added cumulatively. In the event that a particular type of industry was absent from the area, a score of 100 was added to the cumulative sum. When this sun was lowest in value, diversity was greatest, and vice versa. This he called "the crude diversity index" (C.D.I.). Because cases with no employment in some sectors will necessarily have high C.D.I. scores, it is difficult to compare among locations unless they all have employment in all sectors considered. In part to deal with this problem, Tress developed a refined index, which he stated as follows:

$$
\begin{aligned}
& \text { Actual Crude Index - } \\
& \text { Refined Index }=\frac{\text { Crude index for greatest diversity }}{\text { Crude index for least diversity - }} \\
& \text { Crude index for greatest diversity }
\end{aligned}
$$

This index describes diversity in scores ranging from $\theta$ to 1 to facilitate comparison of diversity among different localities, in his case, cities. The closer this index is to 1 , the less is the level of diversification. 


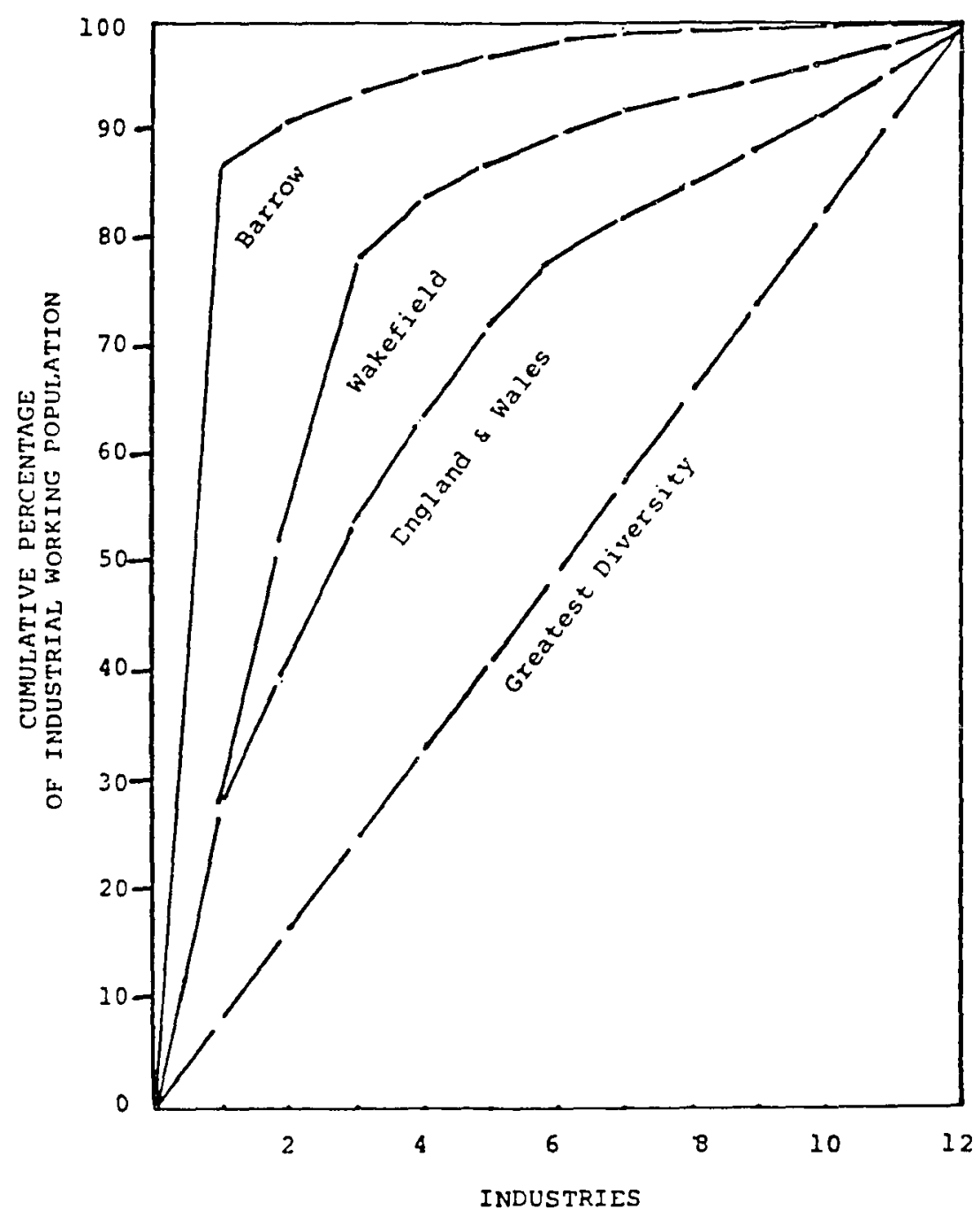

Figure 1. Graphic presentation of the Ogive measure. 
In addition, he uses a Lorenz curve to illustrate his method of comparison graphically (see Figure 1). According to Tress, diversities of different cities can be compared by use of this method. The greatest diversity is achieved when employment is equally distributed among industries (industries 1 to 12 ). This is presented by equidistant points on the diagonal lines as shown in Figure 1. England and Wales are shown to be less than perfectly diversified, while Barrow exhibits the least diversified industrial structure. Yet this argument is somewhat misleading. First, it has never been proven that even distribution of employment constitutes an optimal diversification. Second, industry number one can be mining for England, construction for Wakefield, and electrical equipment for Barrow. Thus, two regions can have identical levels of diversification but a totally different industrial mix. Third, Tress sees diversification only in terms of industrial employment and completely ignores other important sectors of the economy, such as services and government. These two are viable sectors in many regions of Great Britain, the United States, and the rest of the world. Rodgers' (1957) method of measuring diversification differs siightly from that of Tress. Tress used equal employment in twelve major industrial groups as a basis for absolute diversification, and computed deviation from this base as indicators of the degree of diversification or specialization of industrial areas. Rodgers, on the other hand compared

. . the distribution of manufacturing employment by manufacturing groups for individual areas with the average distribution for all of the industrial areas studied, with the latter considered a norm or reference level $(16, p .19)$. 
Of the 168 standard metropolitan areas listed by the Bureau of Census in 1950, Rodgers (1957) chose 93 for his detailed analysis. It should be noted - . that these 93 areas accounted for over 92 percent of the total manufacturing employment in all standard metropolitan areas, and almost two-thirds of the employment in manufacturing in the United States in 1950 (16, p. 17).

Placing his emphasis on manufacturing, Rodgers, like Tress, tended to

obscure the role of other important industries such as retail and wholesale trade, services, and government.

Rodgers found diversification played a limited role in aspects of regional development. For instance, he found that the degree of correlation between seasonal variation and diversification amounted to $.243\left(r^{2}=.0593\right)$. With regards to cyclical variation and diversification, his findings were not much better: an $\mathrm{r}^{2}=.0545$ was obtained. "Again the relationship proved to be statistically insignificant; the diversified areas were no more stable than specialized ones" (16, p. 27). Similarly, with regards to rate of growth, the percentage change in employment was correlated with the crude index of diversification and $\mathrm{r}^{2}$ of .0033 was obtained which hardly describes any significant relationship.

\section{Portfolio Approach}

Harry Markowitz (1952) was first to introduce the concept of the diversified investment portfolio, which he called the E-V Rule. This Rule was expected to provide maximum return on stocks investment with minimum variance. Based on this concept and later work by Tobin (1958) and Sharpe (1970), a new method of measuring industrial diver- 
sification had emerged. Conroy (1972), Barth (1975) and St. Louis (1980) further developed this portfolio approach to industrial diversification.

According to Conroy, every region has a set of human resources which can be used, together with other resources, to generate returns to the community. These streams of returns can be considered stochastic. If this is so, then the region's policy maker should not only consider the expected return, but the dispersions around the mean as we11. For example, before an industry is invited to the region by revenue bond, free site, low taxes, etc.), policy makers should consider not only how many people this industry will employ, but al so how stable this employment will be. To consider a number of industries at the same time is similar to considering, say, a portfolio of stock. This is how the term "industrial portfolio" came about.

If one is to accept, as Conroy suggests, the variance as a measure of the fluctuations or 'risk' to which one is adverse in stochastic processes, the 'portfolio variance' provides an aggregate measure of that risk. He defines this variance $(\sigma \rho)$ as being:

$$
\sigma \rho=\sum_{i} \sum_{j} \omega_{i} \omega_{j} \sigma_{i j}
$$

Where: $\omega_{i}$ and $\omega_{j}$ denote the proportion of regional resources (i.e. employment) allocated to industries $i$ and $j$; and $\sigma_{i j}$ denote the covariance of the predetermined returns criterion over time for industries $i$ and $j$.

This is the same formulation developed earlier by Markowitz (1952) for analysis of personal investment portfolio. Since $\sigma \rho$ is a variance of a weighted sum, it can be disaggregated as follows: 


$$
\sigma_{\rho}=\sum_{j} \omega_{j}^{2} \sigma_{j}^{2}+\sum_{i \neq j} \sum_{i \neq j} \omega_{i} \omega_{j} \sigma_{i j}
$$

Conroy noted that by this reformulation, the significance of the portfolio approach to industrial diversification may be noted more clearly. If a region has an opportunity to invest some of its resources in support of one of two industries with equal expected returns, and if one of those industries had a variance of returns considerably greater than the other, the better choice would not necessarily be the 'less risky' of the two on the basis of their respective variances $\left(\sigma j^{2}\right)$. Every industry contributes to the aggregate regional portfolio variance, not only through the first term on the right hand side, but also through the weighted sum of all covariances with other industries in the portfolio. Regions with lower scores of portfolio variances are more optimally diversified than others. However, low scores can be the result of small variances, small covariances or a combination of both. This is a major criticism of the portfolio measure of diversification. To examine diversification by this criterion, he calculated the portfolio variance for each of fifty-two regions (SMSA) on 3 digits SIC industries. There were a total of 118 sectors at the 3 -digit level.

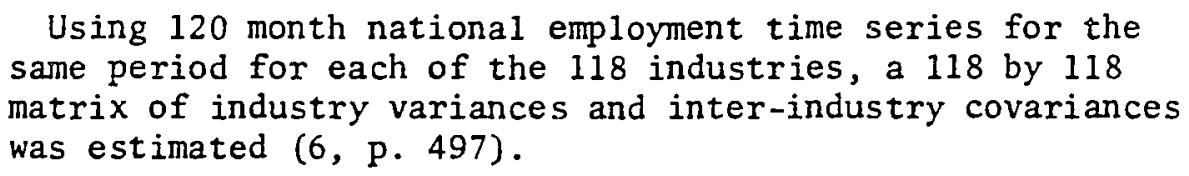

Conroy then estimated for each SMSA a measure of historical instability. "Denoted by $z_{k}$, this measure is defined as:

$$
z_{k}=\frac{120 y_{t}^{k}-\hat{y}_{t}^{k^{\frac{1}{2}}}}{\frac{\bar{y}_{t}^{k}}{118}}
$$


Where: $y_{t}^{k}$ denotes observed employment in region $k$ for month $t$,

$\hat{y}_{t}^{k}$ denotes employment in that region and period predicted by the trend equation, and

$\bar{y}_{y}^{-k}$ denotes the arithmetic average of the respective time series" $(6, p .499)$

The portfolio approach developed by Conroy thus yielded two measures: first, a measure of relative regional diversification $(\sigma \rho)$, and second, an index of instability $\left(z_{k}\right)$. Conroy correlated these two measures for the fifty-two SMSAs over 120 month period with impressive results. He obtained a Pearson correlation coefficient of .658; in other words, the portfolio variance can explain 42.2 percent of the variation in the instability index. For comparison, he also calculated ogive and national average diversification indices for the same period. However, neither of the two measures were able to explain more than five percent.

While his results are impressive, Conroy's method raises certain questions. His use of the covariance $(\sigma i j)$ in the above formulation is one example. The size of the covariance is a function of the unit of measurement. The bigger the unit, the greater the covariance. Therefore, regions with a large working population will have greater covariance among its employment sectors than a smaller region. This in turn, will inflate the portfolio variance $(\sigma \rho)$ of the larger region. Larger regions will appear to have a lower level of diversification when in fact they don't. In other words, this formulation is biased toward large regions. Another questionable item is his use of a 
"national covariance." These questions and others will be discussed in more detail in the research design.

Barth, Kraft, and Wiest's (1975) research objective was similar to that of Conroy. Their aim was to investigate the relationship between industrial mix and employment stability. They used their technique to investigate employment patterns in Virginia during the years 1951-71. They used broader categories of employment, 2-digit SIC Codes as compared to the 3-digit ones employed by Conroy. Nine industries were selected. These were 2-digit categories: (1) contract construction, (2) finance insurance and real estate, (3) government, (4) durable goods, (5) mining, (6) nondurable goods, (7) transportation, (8) services, and (9) wholesale and retail trade. From their variancecovariance matrix, they observed:

\footnotetext{
. . the addition of industry eight to the region would would be desirable since it has a relatively small variance and a negative covariance with industry two, consequently adding little to the variance of regional employment. In contrast, expansion of industry four would not be desirable because its large variance and large positive covariance with each of the industries would add substantially to total risk (3, p. 13).

Unlike Conroy's study, Barth, Kraft, and Wiest were unable to specifically measure the degree of relationship between fluctuation in employment and the level of diversification. Conroy showed that 42.2 percent of employment fluctuation is explainable by diversification. Nonetheless, their findings regarding the behavior of the covariances are of importance to our own proposed study. For example, their findings in regards to positive and negative covariances and the role they can play in the selection of industrial portfolio or the addition of a new industry.
} 
Entropy

Entropy, according to the Encyclopedia of Science and Technology, is "a function first introduced in classical thermodynamics to provide a quantitative basis for the common observation that naturally occurring processes have a particular direction" (12, p. 9). Subsequently, in statistical thermodynamics, entropy was shown to be a good measure of communication. Shannon (1948) has been credited for having laid the foundation for the use of entropy in communication by formulating a mathematical theory of communication. Hackbart and Anderson (1975) attempted to develop a new measure for diversification using Shannon criterion in which an economy's sectors can be denoted by $P_{1}, P_{2} \ldots P_{n}$. Then, the entropy measure of economic diversification is given by:

$$
D\left(P_{1}, P_{2} \ldots, P_{n}\right)=\underset{1}{C} \sum_{i}-P_{i} \log P_{i},
$$

where $\mathrm{C}$ is an arbitrary constant which determines the scale of measurement. It can be seen that $D$ will attain its maximum value when $P_{1}=P_{2}=\ldots P_{n}=\frac{1}{n}$ and $D\left(\frac{1}{n}, \frac{1}{n}, \ldots \frac{1}{n}\right)=C \log n$. Alternatively, minimum entropy is arrived at when one of the $P_{1}=1$ and the remainder are zero. Herein lies the major weakness of the measure. For all practical purposes, it is not much different than Tress' ogive index. In both methods, maximum diversity was attained when employment was equally divided among all sectors. This "maximum" diversification level is not necessarily an optimal condition.

Hackbart and Anderson went on to test the applicability of their new measure for diversification by examining four river-basin regions and the state of Wyoming. Their findings are somewhat disappointing. 
They did not, for example, show how their new measure "provides a precise definition of economic diversification" (11, p. 378). The only thing their findings show is that the regions in question are "more" diversified in 1960 than 1950 and 1940, using their new measure of diversification. Nothing was said about the efficiency or the advantages of the new measure compared to, say, those of Tress, Daley, or many other indices already in use. By their own admission,

. . the measure does not, however, answer the question of what constitutes an optimal diversification pattern, nor does it establish a causal relationship between economic diversification and economic development policy variables (11, p. 378).

Wasylenko and Erickson (1978) echo similar criticisms but went on to test the empirical similarities of the ogive and entropy indices. They compared the two indices in forty-one industrial sectors for each of the 243 SMSAs in the United States in 1970. They found a rank correlation of .98 , a remarkable similarity. This prompted them to conclude that "while entropy is a comparatively new diversity measure, it cannot be expected to produce different results from the long established ogive index" (28, p. 107).

It was stated earlier in this section that it is not imperative to know what constitutes a "fully" diversified economy. What is important, however, is the relationship between diversification and the rate of regional unemployment. To determine this relationship, a number of existing techniques have been evaluated and none have been found to be adequate for the task. The ogive-norm measures seem to differ only in their definition of a norm, and the method of measuring deviation from this norm and do not address optimal structure. The 
entropy measure, unfortunately, is not much better. In fact, it is hardly an improvement on the ogive. They are practically and theoretically identical. The best result by far was obtained by Conroy, through the use of portfolio variance. He was able to show that over forty percent of the fluctuations in employment can be explained by variation in the industrial mix. Unfortunately, this measure ignores unemployment, and instead focuses on fluctuations in employment. An economy can have a stable employment and at the same time suffer from a high rate of unemployment. This is often the case in stagnant or depressed regions throughout the world. In the next section, a model will be offered that can directly describe the relation between an economic diversification and unemployment. A modification of Conroy's method for measurement of diversification will be presented with an independent variable more appropriate to the thrust of this work. 


\section{CHAPTER III}

\section{STUDY DESIGN}

Nearly forty years ago, Tress began his research effort from a premise that employment evenly distributed among all sectors is the ideal situation. The application of entropy by Hackbart and Anderson (1975) rests on a similar notion. Rodgers (1957) proposed an average of 93 industrial areas as a better yardstick in measuring the true diversification level. Conroy (1975) pursued the idea that minimum industrial variance is what ought to be considered, on the premise that this type of mix is likely to be associated with the least amount of employment fluctuations.

The new approach to investigating the effect of diversification on regional unemployment developed here was based on more logical grounds. It is based on the premise that the unemployment rate in a given region is dependent on the nature of the relationship among its economic sectors. For example, how many changes in employment within the construction industry are associated with changes in employment in other industries such as lumber and wood products, services, trade, government, and so forth. It is the nature of these relationships, to some extent, that determines the rate of unemployment.

The construction of the new measure of diversification, the first objective of this research was based primarily on this notion. This measure determined the level of industrial (or sectorial) 
dependence in a region and is referred to as L.I.D. This index, however, is not a measure of direct linkage between industries or sectors in a given region, but rather a measure of the statistical association between the levels of employment.

Because of its relation to Conroy's index, the L.I.D. will be elaborated after a brief review of Conroy's index and relaced statistical theorems. Second, a more detailed description of the data set that was used in the course of this investigation will be given. Third, because a comparative analysis was done, formulations of other alternate measures are presented. Fourth, the procedures used for testing the research hypothesis will be detailed.

Level of Industrial Dependence (L.I.D.)

In the review of the portfolio approach, some questionable items in Conroy's measurement were discussed. Although his results were impressive, his use of some statistical concepts raise some doubts which have bearing on the construction of our L.I.D. measure.

Conroy's measure of industrial diversification is the regional portfolio variance. It is based mainly on earlier methods developed by Markowitz (1952) to choose the right portfolio of stocks for a given investor. Conroy's portfolio variance can be described as a function of some assigned weights $w_{i}, w_{j}$ and the covariance $\sigma_{i j}$.

$$
\hat{\sigma}_{\rho}=\sum_{i=1}^{n} \sum_{j=1}^{n} \quad w_{i} w_{j} \quad \hat{\sigma}_{i j}
$$

The goal of his model was to explore the relationship between industrial mix and fluctuations in regional employment. The use of 
the weights, which in this case are the percentages of sectorial employment, is not objectionable. But, some characteristics of the covariance raise serious questions. From a statistical point of view, the estimator $\hat{\sigma}_{i j}$ is an unbiased and consistent estimator of $\hat{\sigma}_{i j}$, unbiased in the sense that

$$
E\left(\hat{\sigma}_{i j}\right)=\sigma_{i j} \text {. }
$$

That is to say, the mean of the sampling distribution of $\hat{o}_{i j}$ is the value of the parameter $\sigma_{i j}$. The other characteristic of this estimator is consistent. This means that "for limiting a case of a sample of infinite size, the probability that the estimator will have a value which differs by any amount from that of the corresponding parameter is zero" (29, p. 24); more specifically:

$$
\lim _{n \rightarrow \infty} P\left(\left|\hat{\sigma}_{i j}-\sigma_{i j}\right|>\varepsilon\right)=0 \text { for any } \varepsilon>0
$$

Therefore, from the statistical point of view, $\hat{\sigma}_{i j}$ is a good estimator of $\sigma_{i j}$. But when it is used to calculate portfolio variance, it tends to bias the results in favor of large regions. Bigger regions will have a greater portfolio variance. This can be seen in the formulation of the covariance:

$$
\sigma x, y=E\left[\left(X-\mu_{X}\right)\left(Y-\mu_{y}\right)\right] \text { where } \mu=\text { population mean }
$$

If ( 2 ), for example, is equal to (aX), where (a) is a constant, the relationship becomes

$$
\begin{aligned}
E\left(Z-\mu_{z}\right)\left(Y-\mu_{y}\right) & =E\left(a X-a \mu_{x}\right)\left(Y-\mu_{y}\right) \\
& =a E\left(X-\mu_{x}\right)\left(Y-\mu_{y}\right) \\
& =a \sigma_{x y}
\end{aligned}
$$


Therefore, $\sigma_{z, y}$ is not equal to $\sigma_{x, y}$. For example, the covariance between the length of a copper wire and price will be different if the length was to be measured in inches instead of feet. An example developed earlier by Yamane (29, p. 436) illustrates this point. Below are the lengths (in feet) of four copper wires shown together with their corresponding prices.

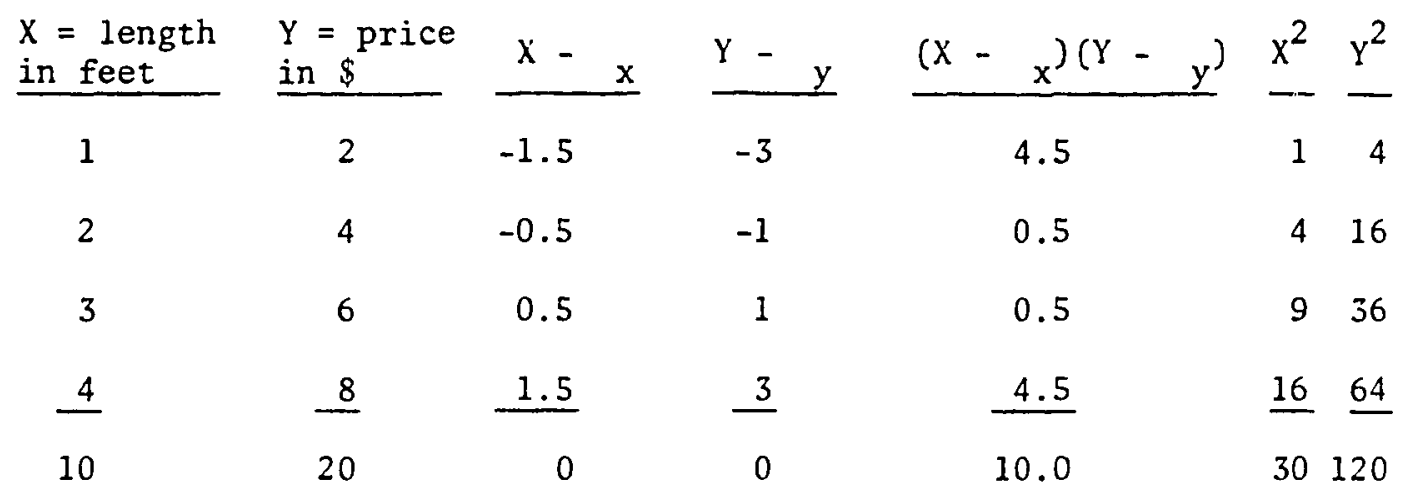

The covariance (Cov) between $X$ and $Y$ is defined as:

$$
\begin{aligned}
\operatorname{Cov}(X, Y) & =E\left(X-\mu_{x}\right)\left(Y-\mu_{y}\right) \\
& =\frac{1}{n} \sum\left(X-\mu_{X}\right)\left(Y-\mu_{y}\right) \\
& =\frac{1}{n}(10)=2.5
\end{aligned}
$$

The coefficient of correlation on the other hand is denoted by $\rho$ and defined as :

$$
\rho=\frac{\operatorname{Cov}(X Y)}{\sigma X \sigma y}
$$

where $\sigma_{X}$ and $\sigma_{y}$ are the standard deviation of $X$ and $Y$ respectively.

The variances of $X$ and $Y$ are denoted by $\sigma_{X}^{2}$ and $\sigma_{y}^{2}$ and calculated as follows: 


$$
\begin{aligned}
\sigma_{x}^{2} & =\frac{1}{n} \sum(x-x)^{2} \\
& =\frac{1}{n} x^{2}-\frac{(\Sigma x)^{2}}{n} \\
& =\frac{1}{n}\left(30-(2.5)^{2}\right. \\
& =1.25 \\
\sigma_{y}^{2} & =\frac{1}{4}(120)-(5)^{2} \\
& =5
\end{aligned}
$$

therefore

$$
\begin{aligned}
\rho & =\frac{\operatorname{Cov}(X,-Y)}{\sigma_{X} \sigma_{y}} \\
& =\frac{2.5}{\overline{1.25} \frac{5}{5}} \\
& =1
\end{aligned}
$$

If on the other hand, the lengths of the copper wire were measured in inches, as shown below, the value of the coefficient or correlation will remain the same while the covariance takes on a new value.

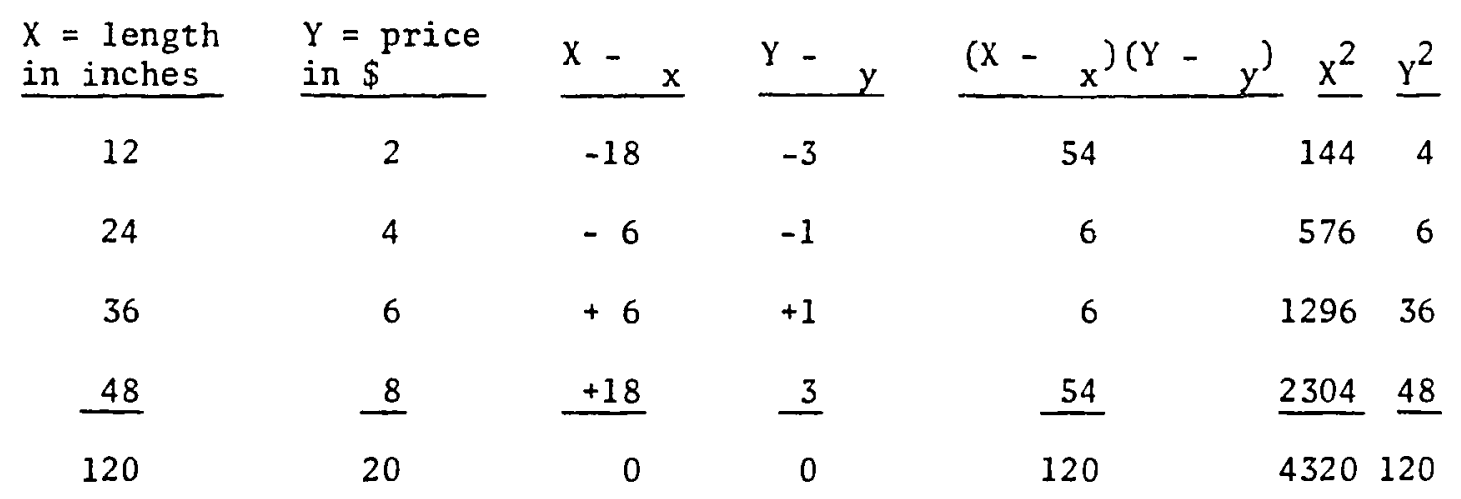




$$
\begin{aligned}
\operatorname{Cov}(X, Y) & =E\left(X-\mu_{X}\right)\left(Y-\mu_{X}\right) \\
& =\frac{1}{n} \sum\left(X-\mu_{X}\right)\left(Y-\mu_{y}\right) \\
& =\frac{1}{n}(120) \\
& =30 \\
\sigma_{X}^{2} & =\frac{1}{n} \sum\left(X-\mu_{X}\right)^{2} \\
& =\frac{1}{n} \sum X^{2}-\frac{(\Sigma X)^{2}}{n} \\
& =\frac{1}{4} \cdot 4320-\frac{(120)^{2}}{4} \\
& =180 \\
\sigma_{y}^{2} & =\frac{1}{4}(102)-\frac{(5)^{2}}{4} \\
& =5
\end{aligned}
$$

Therefore

$$
\begin{aligned}
\rho & =\frac{\operatorname{Cov}(X, Y)}{\sigma_{X} \sigma_{y}} \\
& =\frac{30}{180} \frac{}{5} \\
& =1
\end{aligned}
$$

As can be noted in the calculation above, the value of the coefficient of correlation remained the same $(\rho=1)$ while the covariance has taken a new value of 30 compared to a previous value of 2.5 . Thus, the statistic $r_{i j}$, the coefficient of correlation works better in comparison to the covariance to describe the relationships between industries in our measure of diversification. While $r_{i j}$ and $\sigma_{i j}$ both describe the nature of the relationship (direct or inverse) similarly only $r_{i j}$ can 
determine the degree of that relationship without sensitivity to size problem.

The new measure of diversification, L.I.D., is an index of the level of industrial dependence. It is the sum of the product of the percentages of employment for every pair of industries, times their corresponding coefficient of correlation. The main advantage of L.I.D. over Conroy's measure lies in the use of $r_{i j}$, the coefficient of correlation instead of $\sigma_{i j}$, the covariance is influenced by the unit of measure while $r_{i j}$ is not. L.I.D. can be defined as follows:

$$
\text { L.I.D. }=\underset{i}{\sum} \sum_{j} P_{i} P_{j} r_{i j}
$$

where

$P_{i}$ and $P_{j}$ represent the percentage of employment in industries $i$ and $j$ respectively, $r_{i j}$ is the coefficient of correlation between industries $i$ and $j$.

$P_{i}$ can, for example, represent the percent of the total work force employed in the construction industry, while $P_{j}$ represents the share of the lumber industry. $r_{i j}$ is the coefficient of correlation between construction and lumber industries. It can have a value ranging from -1 to +1 . If the sign of $r_{i j}$ is negative, then it is an inverse relationship. This means that as employment in the construction industry rises, lumber employment falls. If on the other hand the sign is positive, it is a direct relationship which shows that employment in both industries rise and fall together. The percents of employment $P_{i}$ and $P_{j}$ can vary as well. Each can vary from zero to 100 percent. If construction constitutes 100 percent of the employment, then lumber 
must be zero and vice versa. This, however, has never been the case in any county in Oregon. In fact, the standard aggregation of employment data for the counties encompasses at least ten industries or sectors. These ten industries, identified in the following section, constitute the data sets utilized in the course of this investigation.

\section{Data Sets}

Calculation for the L.I.D. index (as well as other indices) is based on employment data of ten different industries. These industries are :

1. Lumber and Wood Products (S.I.C. 24)

2. Other Durable Goods (S.I.C. 25, 32-39)

3. Food Products (S.I.C. 20)

4. Other Non-durable Goods (S.I.C. 21-23, 26-31)

5. Construction (S.I.C. 15-17)

6. Transportation, Communication \& Utilities (S.I.C. 40-49)

7. Trade (S.I.C. 50-59)

8. Finance, Insurance \& Real Estate (S.I.C. 60-69)

9. Services (S.I.C. 70-89)

10. Govermment (Activities 1,2 \& 3)

Because of the poor quality of agricultural employment statistics, it was decided not to include agriculture. The major source of employment data for the ten industries listed above is the Oregon Resident Labor Force, Unemployment and Employment. This is a monthly report provided by the Employment Division, State of Oregon. Employment figures shown in this report represent the sum of covered and uncovered employment. This on-going data gathering activity is a joint effort 
between the U.S. Department of Labor and Employment Divisions in states. This data is available at different levels of aggregation for counties, SMSA's and states. BLS Handbook of Methods (30, p. 27) indicates that the U.S. Bureau of Labor Statistics cooperates in collecting data each month on employment, hours and earnings from a sample of establishments in a11 non-agricultural activities including government. An establishment is defined as an economic unit which produce goods or services, such as a factory, mine or store. Employed persons include both permanent and temporary employees and those who are working either fulltime or part-time. Workers on an establishment payroll who are paid sick leave, on paid holiday or paid vacation, or who work during only a part of the specified pay period are counted as employed. Persons on the payroll of more than one establishment during the pay period are counted in each establishment which reports them. Since proprietors, :he self-employed, and unpaid family workers do not have the status of paid employees, they are not included. Domestic workers in households are excluded from the data for nonagricultural establishments. Government employment statistics refer to civilian employees only. While the first objective of this investigation focuses on the development of a new measure of economic diversification, the second seeks to determine the effect of economic diversification on regional unemployment. Stinson (1977) points out that when workers are unemployed, their families and the country as a whole are losers. Workers and their families lose wages; the country loses the goods or services which could have been produced. Furthermore, when many people are out of work, the decline in purchasing power can lead to unemployment of other workers and cause additional hardships for the community as a 
whole. Oregon has suffered in recent years from a severe unemployment problem exceeding the national norm. In several counties, unemployment rates reached a level of two to three times that of the national average. Economic diversification is seen in Oregon as a strategy to alleviate the problem of high unemployment. The concern is not how to increase the labor supply, but how to reduce the number of those who are already unemployed.

The source of unemployment statistics is the Current Population Survey (CPS) conducted monthly by the Bureau of Labor Statistics in conjunction with state governments. Persons are characterized as unemployed if they have actively look for work and are currently available for work. A person is not counted as unemployed if he or she is waiting to start a new job in 30 days or waiting to be called from layoff. One systematic deficiency with this definition is the fact that a person, after a long period of time, may give up looking for a job and hence not be counted as unemployed. However, there are no available statistics to correct this omission. Twenty-nine counties, plus three SMSA's are considered in the calculation of the L.I.D. index and other measures of diversification for a total of 32 cases. Some of these SMSA's may contain only one county as is the case in Eugene. The Portland SMSA, on the other hand, contains four counties while Salem includes two.

\section{Formulation of Other Measures}

The L.I.D. measure presented earlier is based on a new perception or approach to the concept of economic diversification. As detailed in Chapter II, there are three other approaches. A thorough analysis of 
the problem of diversification is not complete without comparing the results derived by the use of other indices. Therefore, these indices are calculated and the obtained results are used to further test the major hypothesis. Because of its extreme similarity to the ogive, it is not necessary to use the entropy measure. Further discussion of this point is included in Chapter II.

The formulation of the portfolio approach was presented earlier (page 12). The ogive measure can be defined as follows:

$$
D_{0}=n_{i=1}^{n}\left(P_{i}-\frac{1}{n}\right)^{2}
$$

where $P_{i}$ is the proportion of employment in the ith industry and $n$ is the number of industries.

The national norm measure uses a set of nation-wide proportions and compares those with states or regional proportions. Florence (1948) evaluated the diversity among states by comparing the absolute value of differences between states' shares and the national proportion. Formally:

$$
D_{F}=\quad \sum{ }_{i}=1 \frac{\left(P_{i}-m_{i}\right)}{m_{i}}
$$

where

$P_{i}$ is the state proportion of employment in the ith industry $m_{i}$ is the national proportion of employment in the ith industry. Rodgers (1957) substituted an average of 93 SMSA's for the national norm. In either case, the basic idea is to compare regional proportions to an acceptable norm. It is perfectly logical to compare state proportions of employment with those of the nation, but the same 
cannot be said for comparing Oregon counties with the national norm. Therefore, in calculating Florence's index, the state of Oregon proportions were used as the desired norm.

Florence's norm, ogive, Conroy's portfolio variance and the L.I.D. index were calculated in a cross-sectional study of Oregon's 29 counties and three SMSA's. In the case of Conroy's measure, a state-wide covariance was used. Similarly, a state-wide coefficient of correlation was used in calculating the L.I.D. index. Both the covariance and the coefficient of correlation were calculated using employment statistics of ten previously selected industries or sectors.

In addition, the L.I.D. index was calculated in a longitudinal study of two specially selected counties, Morrow and Harney. It covered a six-year period beginning January 1, 1975 and ending December 30, 1980. As indicated earlier, Morrow and Harney Counties are two extreme cases of unemployment. Morrow enjoyed low rate of unemployment which had been attributed to the diversified nature of its economy. Harney, on the other hand, claimed the highest rate of unemployment and is considered to be the least diversified, with a heavy dependence on timber.

As stated earlier, there are two objectives to this dissertation. The first is to develop a more appropriate measure of economic diversification, and the second is to test the hypothesis regarding the effect of diversification on unemployment. What has been accomplished thus far is the development of a new measure of economic diversification, the L.I.D., and the presentation of the rationale behind it. In the next section, a procedure for meeting the second objective is presented. 


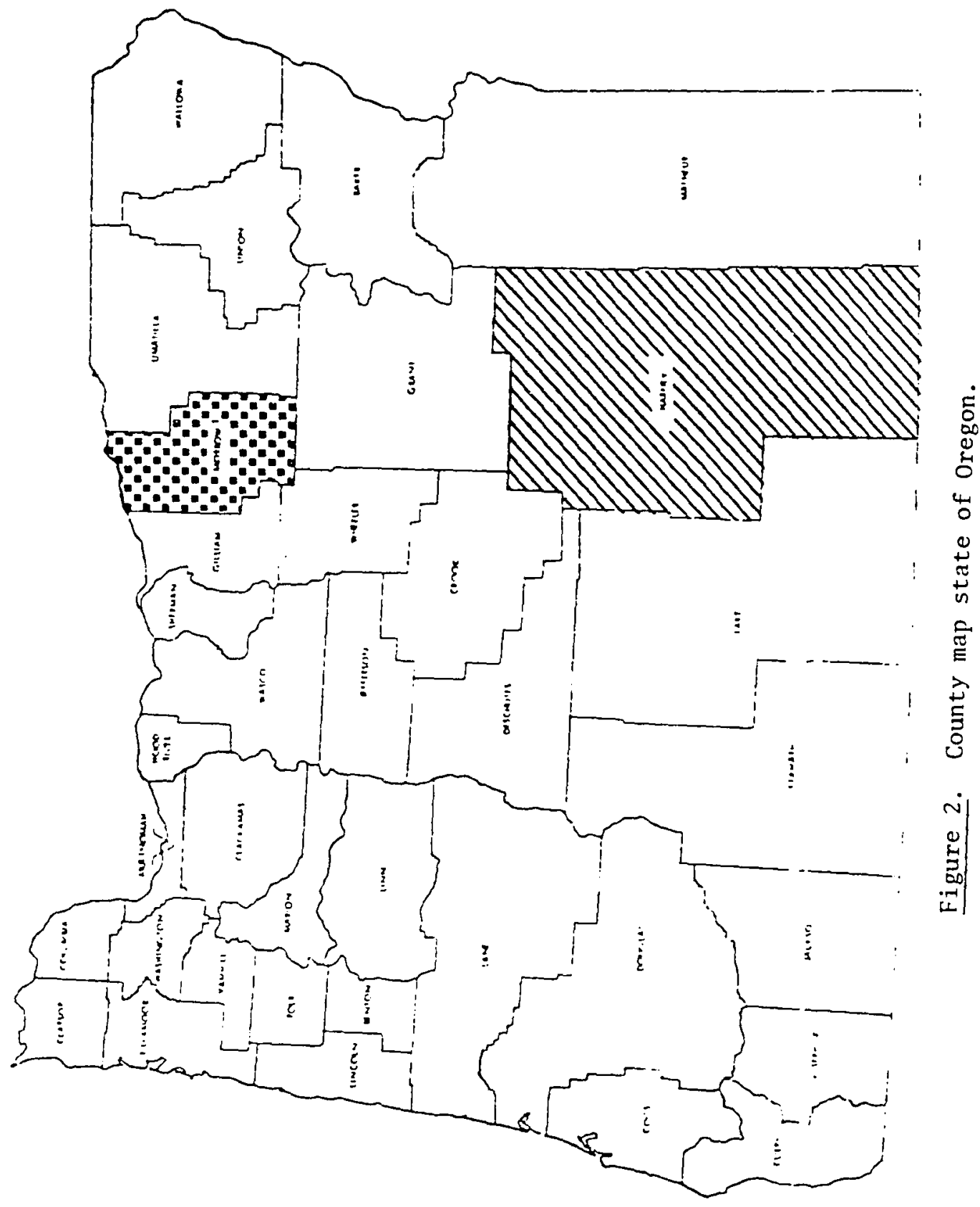


Hypothesis Testing

The second objective of this dissertation is to test the hypothesis that:

There is no relationship between the level

of economic diversification in a region and

its rate of unemployment.

Two types of information are necessary for this task. One is a set of observations on the levels of diversification, and the other is a similar number of observations on the rates of unemployment. The first set of observations are based on calculations of the L.I.D. and other measures of diversification. The second set of data has been gathered from publications by the State of Oregon, Division of Employment. Once this data is assembled, the hypothesis was tested through the use of the normal error regression model. This model is defined as:

$$
\mu_{i}=\beta_{0}+\beta_{1} D_{1}+\varepsilon_{i}
$$

where

$\mu_{i}$ is the value of the dependent variable (unemployment) in the ith trail.

$D_{i}$ is the value of the independent variable (diversification) in the ith trail.

$B_{0}$ and $B_{1}$ are parameters

$\varepsilon_{i}$ is independent of $\varepsilon_{j}$ for $j \neq i$, and so

$$
E\left[\left(\varepsilon_{i}-\mu_{\varepsilon}\right)\left(\varepsilon_{j}-\mu_{\varepsilon}\right)\right]=C_{o v}\left(\varepsilon_{i}, \varepsilon_{j}\right)=0
$$

The latter assumption proved of significant importance in the longitudinal study of Morrow and Harney Counties. There are other methods 
which can be used to test a null hypothesis besides regression analysis. However, a regression model was chosen because it not only can test a null hypothesis, it can also predict a new observation. This is to say that if the level of diversification is known, the rate of unemployment can be predicted. Both hypothesis test and an operational model are attainable by this technique.

The statistical hypothesis is that $\beta_{\downarrow}=0$. This task can be accomplished by three different procedures. Netter and Wasserman $(31$, p. 60$)$ outline these three approaches as follows:

Since $\left(b_{1}-B_{1}\right) / s\left(b_{1}\right)$ is distributed as $t$ with $n-2$ degrees of freedom (where $b_{1}$ is the estimate of $\beta_{1}$ and $s\left(b_{1}\right)$ is the standard error), the hypothesis is tested using the $t$ distribution. The two alternatives are:

$$
\begin{aligned}
& C_{1}: B_{1}=0 \\
& C_{2}: B_{1} \neq 0
\end{aligned}
$$

If the level of significance is set at $\alpha$, the action limits for testing the above hypothesis would be:

$$
\begin{aligned}
& A_{1}=0-t(1-\alpha / 2 ; n-2) s\left(b_{1}\right) \\
& A_{2}=0+t(1-\alpha / 2 ; n-2) s\left(b_{1}\right)
\end{aligned}
$$

and the decision rule would be:

$$
\begin{aligned}
& \text { if } A_{1}<b_{1}<A_{2} \text {, conclude } C_{1} \\
& \text { if not, conclude } C_{2} \\
& \text { An equivalent alternative to the above approach is through the }
\end{aligned}
$$
use of test statistic $t^{*}$ : 


$$
t^{*}-\frac{b_{1}}{s\left(b_{1}\right)}
$$

Here the decision rule when controlling the level of significance at $\alpha$ is:

$$
\begin{aligned}
& \text { If }\left|t^{*}\right|<t(1-\alpha / 2 ; n-2) \text {, Conclude } C_{1} \\
& \text { If }\left|t^{*}\right|>t(1-\alpha / 2 ; n-2) \text {, Conclude } C_{2}
\end{aligned}
$$

A rule of thumb often used by econometricians is that if the $t$ * ratio exceeds in absolute value 2 , the null hypothesis that $b=0$ ought to be rejected. If this ratio is more than 3, the null hypothesis will certainly be rejected.

In addition, the $F^{*}$ test is often used as a means of testing the null hypothesis regarding $\beta_{1}$. It is defined as:

$$
F^{*}=\frac{M S R}{M S E}
$$

where MSR is the sum of squares, $\sum \Sigma(\hat{y}-\bar{y})^{2}$, divided by one degree of freedom and MSE is the error sum squares, $\left(\sum\left(y_{i}-y_{i}\right)^{2}\right.$, divided by $n-2$ degree of freedom. The decision rule for the $F^{*}$ test at level of significance is:

$$
\begin{aligned}
& \text { If } F^{\star} \quad F(1-\alpha ; 1, n-2) \text {, Conclude } C_{1} \\
& \text { If } F^{\star} \quad F(1-\alpha ; 1, n-2) \text {, Conclude } C_{2}
\end{aligned}
$$

where $F(1-\alpha ; 1, n-2)$ is the $(1-\alpha) 100$ percentile of the $F$ distribution. The S.P.S.S. statistical package contains these statistics. 
CHAPTER IV

APTNESS OF DIVERSIFICATION MEASURES

This research effort is based on two objectives: one is to develop a more appropriate measure of diversification; the other is to test the null hypothesis that there is no relationship between economic diversification and the rate of unemployment. In this chapter, research findings related to the first objective are discussed. Relationships between diversification and unemployment are examined in the following chapter.

Table I summarizes the results of four regression runs dealing with the various measures of diversification. It is evident that the newly developed measure of diversification, L.I.D. is far superior in explaining the relationship between diversification and unemployment. The L.I.D. has an $\mathrm{R}^{2}$ of 0.27898 compared to the 0.06375 of the regression on the Conroy measure and insignificant association with the other measures.

TABLE I

REGRESSION RESULTS CROSSSECTIONAL STUDY

\begin{tabular}{lcccr}
$\begin{array}{l}\text { Diversification } \\
\text { Index }\end{array}$ & $\mathrm{b}_{1}$ & $\left.\mathrm{~s}_{\mathrm{l}} \mathrm{b}_{1}\right)$ & $\mathrm{R}^{2}$ & $\mathrm{~F}$ \\
\hline Florence & -0.00242 & 0.01210 & 0.00133 & 0.03992 \\
Ogive & 0.01444 & 0.01392 & 0.03463 & 1.07612 \\
Conroy & -0.06907 & 0.04833 & 0.06375 & 2.04256 \\
L.I.D. & -0.05979 & 0.01755 & 0.27898 & 11.60789 \\
\hline Level of significance $\alpha=0.05$ & &
\end{tabular}


Florence's index produced an $\mathrm{R}^{2}$ of only 0.00133 . Diversification, as defined here, is not a very good predictor of the level of unemployment. Less than one percent of the variation in unemployment can be explained by variation in the level of diversification. This less than adequate performance compared to the L.I.D. can only be explained by the nature of the measure. First, there is no evidence that any norm, be that of state, nation, or group of SMSAs, is the ideal level of diversification. Furthermore, if the norm (state, nation, or SMSA) is in recession, it can hardly be ideal. These deficiencies are not limited to geographical norms, but also are prevalent in graphic or mathematical norms, such as the ogive.

The ogive exhibits a slight improvement in predicting unemployment compared to Florence's. An $\mathrm{R}^{2}$ of 0.03463 is somewhat of an improvement on the 0.00133 . The change in the sign of the parameter $(B)$ is also significant. In the case of Florence's measure, the sign was negative. This meant that the more diversified the region became, the lower its unemployment rate. The ( $B$ ) parameter of the ogive index is positive. This means that as the diversification level increases, so will the rate of unemployment. Both of these indices deal with the pattern of distribution of employment as the measure of econonic diversification. The L.I.D. measure defines diversification in terms of the relationship among economic sectors while Conroy describes diversification in terms of Portfolio Varrance.

Conroy's measure of diversification is superior to the Florence and the ogive. It explained more than six percent in the variations in unemployment. Nonetheless, its results are disappointing. It can be 
recalled from our earlier review of the Portfolio Variance that Conroy claimed an $R^{2}$ of 0.4220 . This is a great deal different from the results we obtained when we calculated the Portfolio Variance for the purpose of comparison. These differences are explainable because a different dependent variable is involved.

The L.I.D. index is able to explain nearly 28 percent of the variations in the rate of unemployment. This is four times the explanatory power of Conroy's index. This claim is further sibstantiated by the high value of the $F^{*}$ statistic which is 11.60789 compared to Conroy's 2.04256. Exhibits 1 through 4 in Appendix A and Exhibits 5 through 7 in Appendix B illustrate in detail the results of these regression runs. The longitudinal study ( $1975-1980)$ using the L.I.D. did not produce a significant association. This is not the result of a deficiency in the concept of diversification, but rather a problem of autocorrelation. This often occurs in time-series analysis. The problem is most evident in the case of Harney County in comparison to Morrow County.

As can be seen in Table II, the L.I.D. measure for Morrow County explains more than 10 percent of the variation in unemployment.

TÁBLE II

REGRESSION RESULTS

LONGITUDINAL STUDY

\begin{tabular}{lccccc} 
County & $\mathrm{b}_{1}$ & $\mathrm{~s}_{1}\left(\mathrm{~b}_{1}\right)$ & $\mathrm{R}^{2}$ & $\mathrm{~F}$ & $\mathrm{D}-\mathrm{W}^{*}$ \\
\hline L.I.D. - Morrow & -0.00618 & 0.00392 & 0.10146 & 2.4840 & 1.80431 \\
L.I.D. - Harney & 0.01226 & 0.01729 & 0.02220 & 0.4994 & 0.52530 \\
\hline
\end{tabular}

*Durbin-Watson Test

Level of significance $\alpha=0.05$ 
In the case of Harney County, only 2.2 percent of the variations is explained. The problem again is a clear case of autocorrelation. This is evident from the result of the Durbin-Watson test shown in Exhibit 7 (Appendix B). This test is defined by Netter and Wasserman (32, p. 352) as follows:

$$
D=\sum_{t=2}^{n} \frac{\left(e_{t}-e_{t-1}\right)^{2}}{t^{n}=1 e_{t}^{2}}
$$

where $e \quad$ is the error term in period $t$

$e_{t-1}$ is the error term in period $t-1$ and

$n \quad$ is the number of observations

An upper and lower bound of 1.49 and 1.35 were obtained from the D-W Table at a level of significance of 0.05 . A D-W value of 0.53361 for Harney County (as shown in Table II) is less than 1.35 which clearly indicates a case of autocorrelation.

Further confirmation is given by the residuals plot illustrated in the left side of Figure 3, with close points more alike than otherwise. This phenomena, according to Netter and Wasserman (32, p. 352) can have serious consequences, such as:

1. The regular least squares regression coefficients are still unbiased, but no longer have the minimum variance property and may be quite inefficient.

2. Main Standard Error may seriously underestimate the variance of the error terms. 
3. $s\left(b_{k}\right)$ calculated according to the regular least squares procedure may seriously underestimate the true standard deviation of the estimated regression coefficient with that procedure.

4. The confidence intervals and tests using the $t$ and F distributions, are no longer applicable.

Another factor which could have contributed to the weak results in the case of Harney is the extraordinary variations in the rates of unemployment of 1980. Figures 4, 5 and 6 illustrate the fluctuations in the rate of unemployment over a six-year period, 1975-1980. A few months in the summer of 1980 can perhaps best be described as outliers. In such a situation, the fitted line is pulled disproportionately toward the outlier in order to minimize the sum of the squared deviations. This would definitely effect the predictability of the model and will greatly reduce our ability to test the null hypothesis.

Quantitative measures are sometimes compared in terms of their validity, accuracy, precision and reliability. Validity according to Kimble "refers to the extent to which a measure predicts something important about the object of measurement (31, p. 188). One method of comparing predictability is through the use of $z$ scores and $R^{2}$. The rule proposed by Kimble can be defined as:

$$
z_{x}=r_{x y} \cdot z_{y}
$$

Where $z_{x}$ is unemployment in $z_{y}$ scores, $z_{y}$ is the level of diversification and rxy the coefficient of correlation (both in $z$ scores). One problem with this rule is that point estimation varies from one 


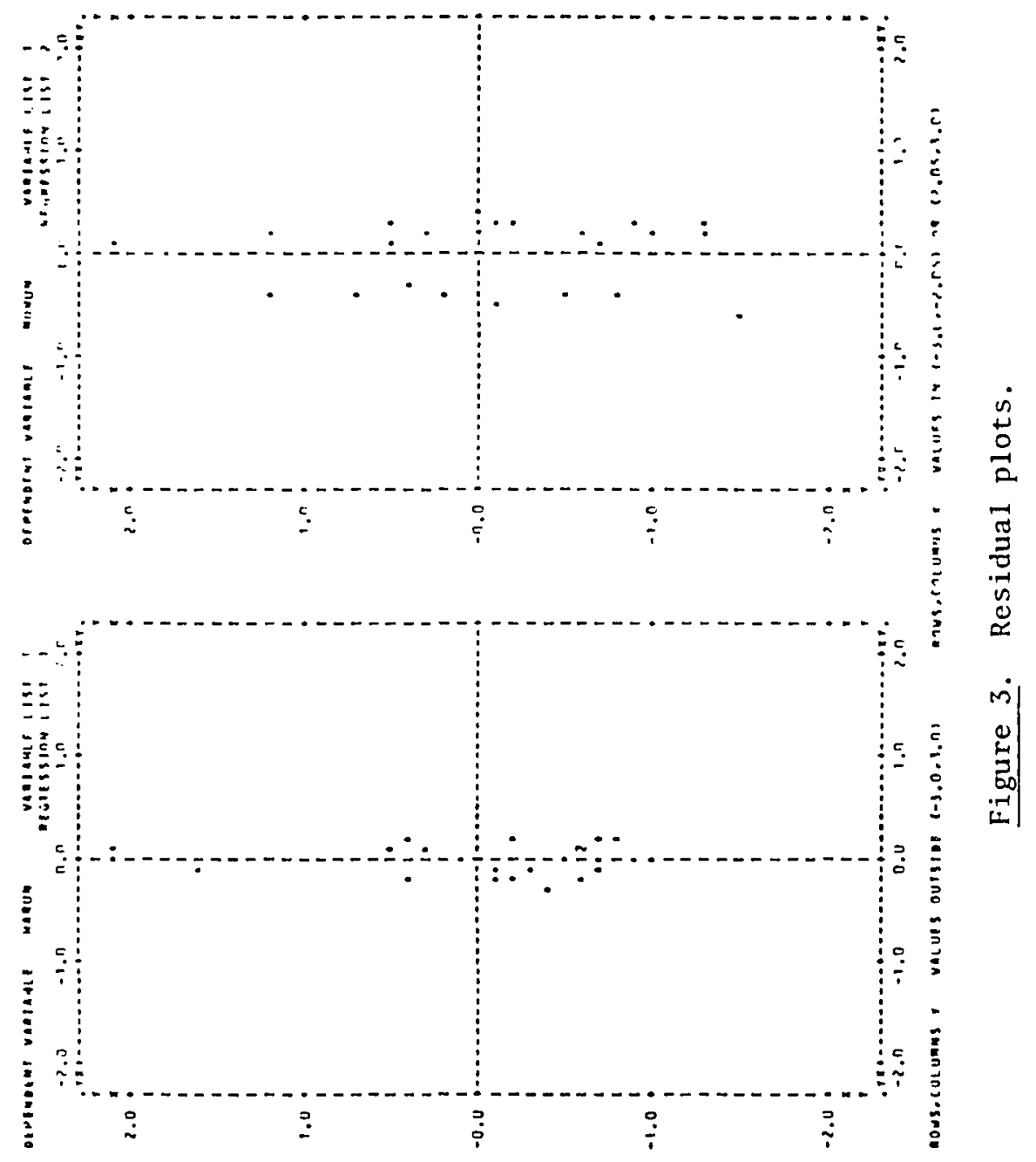




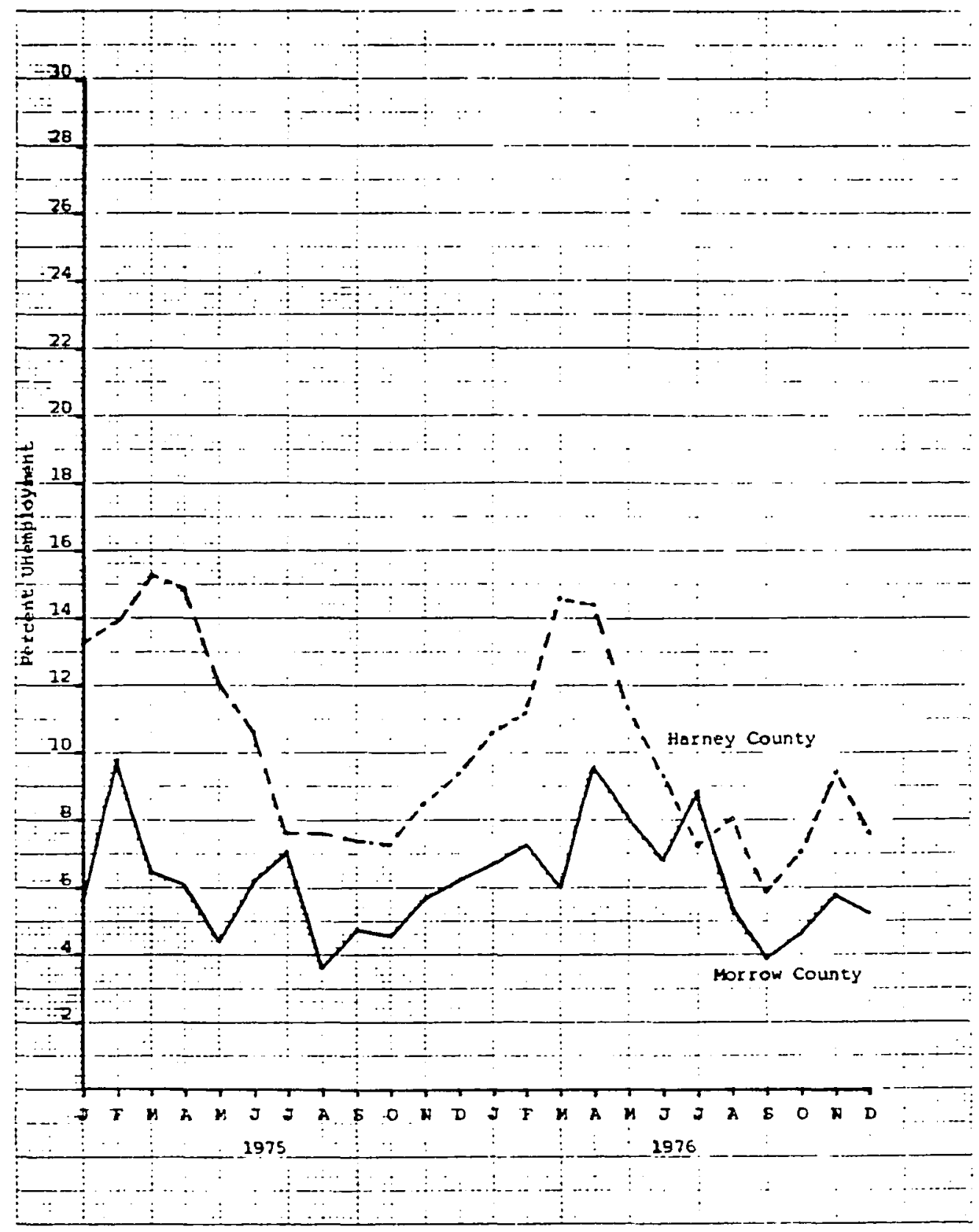

Figure 4. Unemployment rates Morrow and Harney counties. 


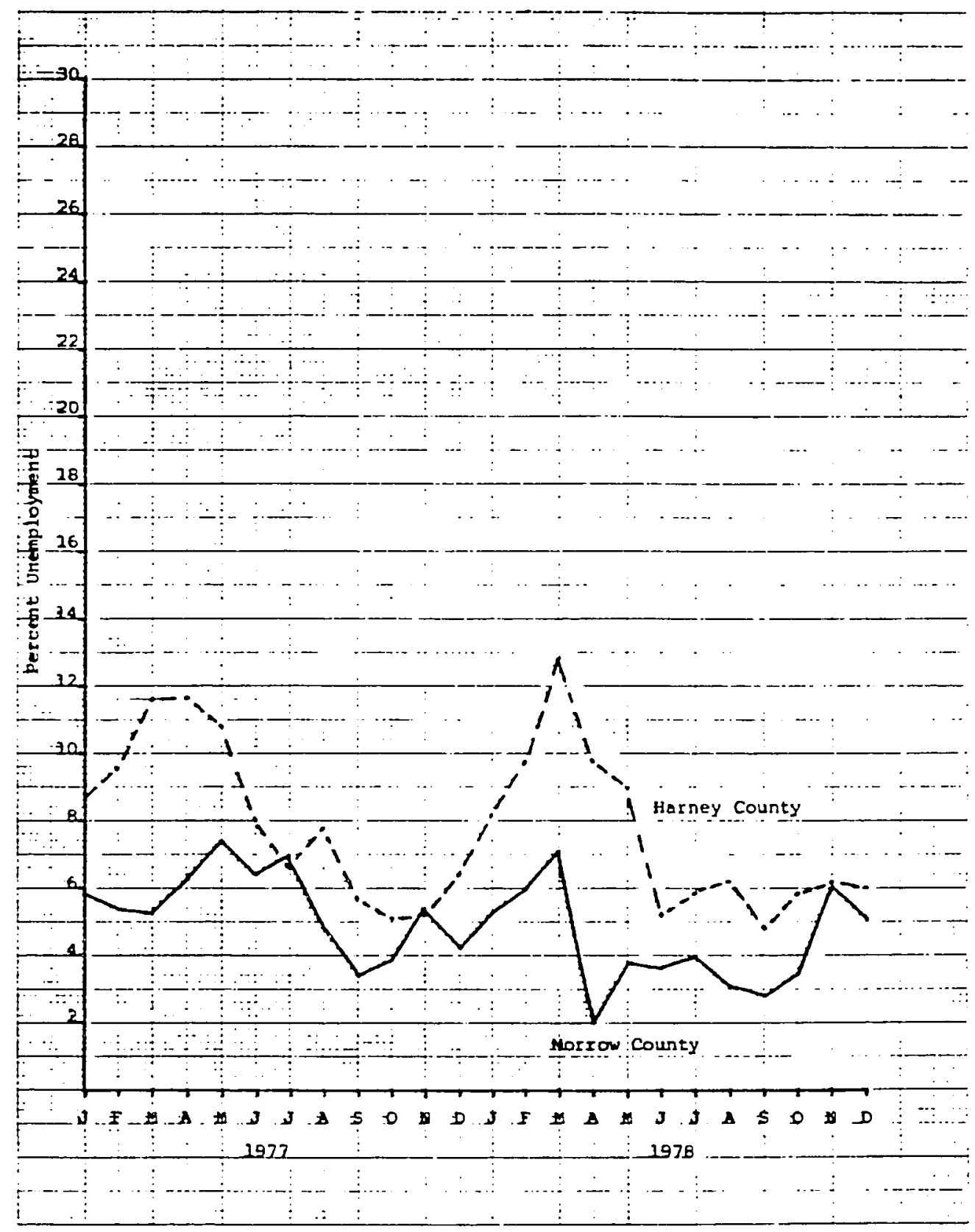

Figure 5. Unemployment rates Morrow and Harney counties. 


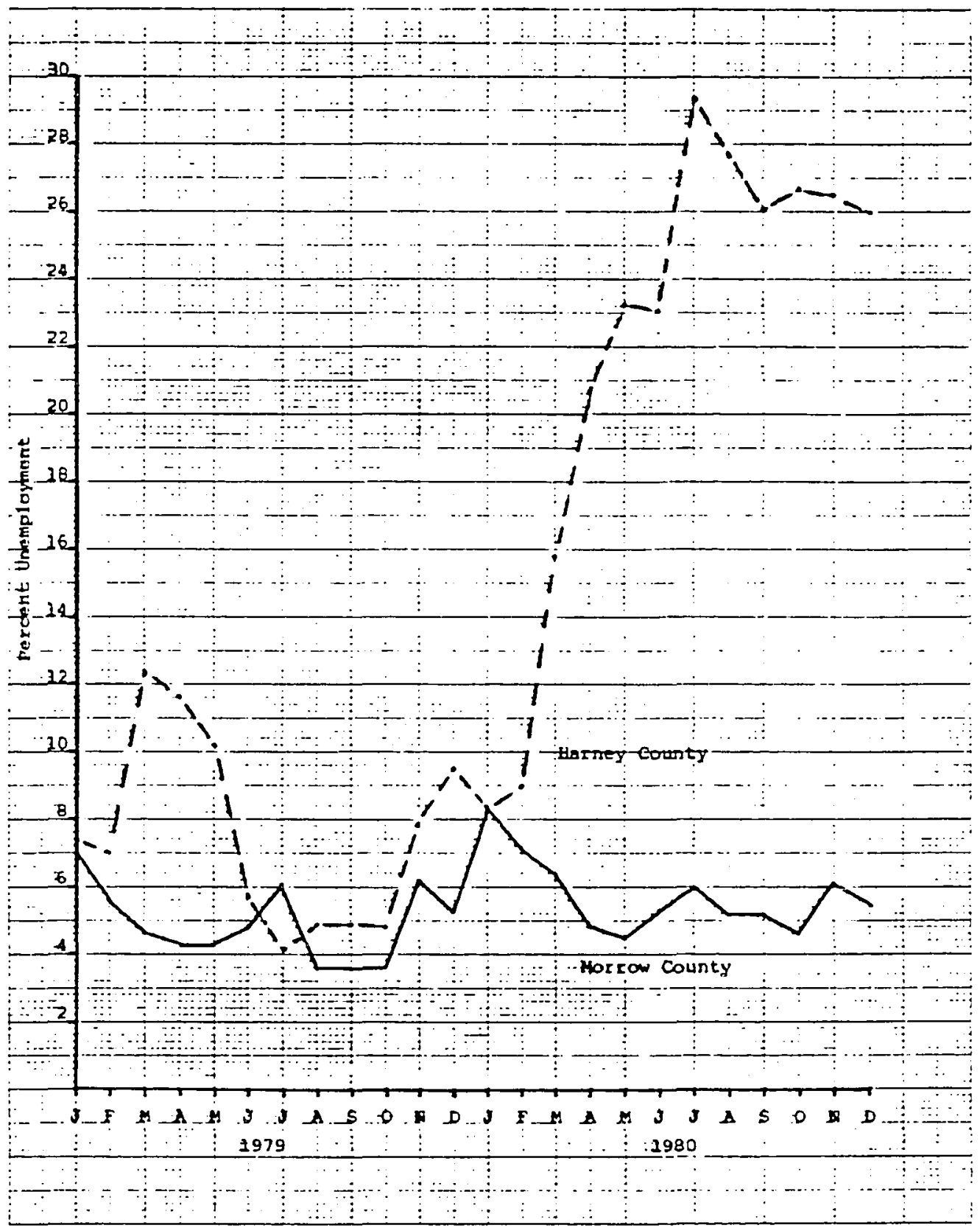

Figure 6. Unemployment rates Morrow and Harney counties. 
regression line to another. For example, a point on the fitted line may or may not yield the best predicted value. Since $\mathrm{R}^{2}$ is the indicator of best fit, comparison of predictability among the four measures can be made by examining their respective $R^{2}$ values. As indicated in Table I, the L.I.D. measure carries the highest value of 27 percent followed by Conroy, ogive and Florence. Table III illustrates the range of values for each of the four measures. The L.I.D. measure emerges as the most precise of the four measures with a range of 1332 . This is only 50 percent of the lower value. Conroy's measure has the highest range of 617460 and a low value of 315306 . The range in this case is approximately 200 percent of the lower value. The ogive nas a range of 2322 which is five and one-half times the lower value. Florence has a range of 2799 and a low value of 75 . It has, by far, the widest dispersion.

It becomes difficult to identify which of the four measures is the most accurate. Although each of these indices measures the level of diversification, each definition of diversification varies. The L.I.D., for example, defines diversification in terms of the degree of independence among the various economic sectors in a given region. Conroy's defines diversification with respect to Portfolio Variance. The Florence and the ogive identify diversification as dispersions from given norms.

Reliability, according to Kimble, "refers to the extent to which a test or other measure performs consistently" (31, p. 186). A ruler, for example, is a reliable measure while a rubber string is not. Therefore, to determine the reliability of any measure, one has to measure the 
TABLE III

VALUES OF DIVERSIFICATION MEASURES AND UNEMPLOYMENT RATES BY COUNTY

\begin{tabular}{|c|c|c|c|c|c|}
\hline County/SHSA & $\begin{array}{c}\text { Percent } \\
\text { Unemployment }\end{array}$ & Florence & Ogive & L.I.I. & Conroy \\
\hline $\begin{array}{l}\text { Baker } \\
\text { Benton } \\
\text { Clatsop } \\
\text { Columbia } \\
\text { Coos } \\
\text { Crook } \\
\text { Curry } \\
\text { Deschutes } \\
\text { Douglas } \\
\text { Gilliam } \\
\text { Grant } \\
\text { Harrey } \\
\text { Hood River } \\
\text { Jackson } \\
\text { Jefferson } \\
\text { Josephine } \\
\text { Klamath } \\
\text { Lake } \\
\text { Lincoln } \\
\text { Linn } \\
\text { Malheur } \\
\text { Morrow } \\
\text { Tillamook } \\
\text { Umatilla } \\
\text { Union } \\
\text { Wallowa } \\
\text { Wasco-Sherman } \\
\text { Wheeler } \\
\text { Yamhill }\end{array}$ & $\begin{array}{l}13.1 \\
6.7 \\
9.4 \\
10.0 \\
14.1 \\
16.5 \\
12.0 \\
11.8 \\
12.4 \\
4.9 \\
14.4 \\
22.1 \\
9.6 \\
10.4 \\
8.0 \\
13.0 \\
10.1 \\
11.3 \\
8.8 \\
10.9 \\
8.3 \\
5.8 \\
9.8 \\
7.6 \\
8.4 \\
9.1 \\
7.7 \\
12.7 \\
7.9\end{array}$ & $\begin{array}{r}124 \\
349 \\
305 \\
467 \\
320 \\
1118 \\
407 \\
126 \\
611 \\
271 \\
689 \\
330 \\
149 \\
92 \\
210 \\
126 \\
453 \\
625 \\
243 \\
220 \\
878 \\
2874 \\
309 \\
506 \\
238 \\
338 \\
75 \\
1004 \\
92\end{array}$ & $\begin{array}{r}964 \\
1459 \\
550 \\
490 \\
673 \\
1016 \\
938 \\
606 \\
790 \\
1305 \\
1655 \\
1004 \\
700 \\
793 \\
887 \\
730 \\
828 \\
1574 \\
732 \\
378 \\
1035 \\
637 \\
781 \\
682 \\
848 \\
961 \\
951 \\
2684 \\
362\end{array}$ & $\begin{array}{l}3668 \\
3451 \\
3808 \\
3667 \\
3479 \\
2924 \\
3334 \\
3470 \\
3288 \\
3615 \\
2967 \\
3295 \\
3705 \\
3629 \\
3324 \\
3577 \\
3343 \\
2965 \\
3762 \\
3623 \\
3789 \\
3705 \\
3446 \\
3883 \\
3518 \\
3255 \\
3771 \\
2726 \\
3429\end{array}$ & $\begin{array}{l}857592 \\
842159 \\
660951 \\
582183 \\
631851 \\
550038 \\
655361 \\
761616 \\
583367 \\
932766 \\
602160 \\
695153 \\
789783 \\
810647 \\
825296 \\
788837 \\
658556 \\
637507 \\
828616 \\
618291 \\
771963 \\
315306 \\
683568 \\
732809 \\
749141 \\
680809 \\
780792 \\
573999 \\
554891\end{array}$ \\
\hline $\begin{array}{l}\text { Portland SMSA } \\
\text { Eugene SMSA } \\
\text { Salem SMSA }\end{array}$ & $\begin{array}{l}6.2 \\
9.8 \\
7.7\end{array}$ & $\begin{array}{r}88 \\
96 \\
168\end{array}$ & $\begin{array}{l}599 \\
723 \\
853\end{array}$ & $\begin{array}{l}4058 \\
3628 \\
3804\end{array}$ & $\begin{array}{l}898337 \\
787802 \\
803393\end{array}$ \\
\hline
\end{tabular}


same object twice and compare the results. This was not possible in the case of this investigation because the initial sample was made up of all the 38 counties and SMSA's in the State of Oregon. Based on this research, one recommendation discussed in detail later considers the development of samples from various parts of the country. 


\section{CHAPTER $V$}

\section{THE RELATIONSHIP OF ECONOMIC DIVERSIFICATION}

TO UNEMPLOYMENT RATE

The second objective of this dissertation is to test the hypothesis that there is no relationship between diversification and unemployment. In other words, to test the Null Hypothesis that $B_{1}=0$. Based on the results of the regression runs presented in the previous chapter, we can now carry out the necessary calculations to accept or reject the Null Hypothesis. Following the first procedure outlined in the study design (Chapter III), the decision rule regarding $A_{1}$ and $A_{2}$ can now be evaluated where:

$$
\begin{aligned}
& A_{1}=0-t(1-\alpha / 2 ; n-2) s\left(b_{1}\right) \\
& A_{2}=0=t(1-\alpha / 2 ; n-2) s\left(b_{1}\right)
\end{aligned}
$$

and the decision rule is:

If

$$
A_{1}<b<A
$$

we conclude that

$$
B_{1}=0
$$

In our case with a level of confidence $\alpha=.05$, we have:

$$
\begin{aligned}
A_{1} & =0-(2.042)(0.0175) \\
& =-0.0357 \\
A_{2} & ==0.0357
\end{aligned}
$$

since $b_{1}=-0.05979$ which is less than -0.0357 , we can reject the Null Hypothesis that $\beta_{1}=0$. 
The second procedure calls for the value of $t^{*}$ which is defined as :

$$
|t *|=\frac{b_{1}}{s\left(b_{1}\right)}
$$

and the decision rule is that if the absolute value of $t^{*}$ and is greater than two, we ought to reject the Null Hypothesis. If this ratio is greater than three, we should immediately reject the Null Hypothesis. The $t^{*}$ value (Table 1 ) in our case is:

$$
\left|t^{*}\right|=\frac{b_{1}}{s\left(b_{1}\right)} \quad \frac{0.05979}{0.01755}=3.4
$$

Therefore we can reject the Null Hypothesis that $B=0$.

The third procedure examines the value of the statistic $F^{*}$ and the decision rule is

$$
\begin{aligned}
& \text { If } F^{*}<F(1-\alpha ; 1, n-2) \text { we conclude } \beta_{1}=0 \\
& \text { If } F^{*}>F(1-\alpha ; 1, n-2) \text { we conclude } \beta_{1} \neq 0
\end{aligned}
$$

From the F Table, we obtain in this case a value of (4.17) and from Table I or Exhibit 4, we note an $F$ value of $(11.60)$. Since $11.60>4.17$, we can conclude that $B_{1} \neq 0$ and therefore reject the Null Hypothesis. In summary, we can conclude that there is a systematic relationship between the level of economic diversification and the rate of unemployment.

This relationship, however, is not as strong as previcusly envisioned. At best, economic diversification can explain only 27 percent of the changes in regional unemployment. Neither was expected as the sign of this relationship. A negative sign was found which indicates that as L.I.D. (Level of Industrial Dependence) increases, unemployment 
decreases. This was also the case for Florence's and Conroy's measures of diversification. One possible explanation is that in small rural counties, the local economy tends to be self-sufficient; the various sectors are the markets and supplies for one another. This is not the case where the entire aconomy is geared for the production of one item to be sold elsewhere, but it is rather the case of inter-community reliance.

The notion of inter-community reliance has some evidence. Table IV contains a list of selected counties in the state of Oregon. Harney, Crook, Grant, and Coos have the highest unemployment rate in the state in 1980 .

\section{TABLE IV}

PERCENT UNEMPLOYMENT L.I.D. AND COEFFICIENTS OF CORRELATION FOR SELECTED COUNTIES, 1980

\begin{tabular}{lccc} 
Counties & $\begin{array}{c}\text { Percent* } \\
\text { Unemployment (1980) }\end{array}$ & L.I.D. & $\begin{array}{c}\text { Coefficients } \\
\text { Of Correlation }\end{array}$ \\
Harney & 22.1 (highest) & 3295 & 0.7005 \\
Crook & 16.5 & 2924 & 0.8948 \\
Grant & 14.4 & 2967 & 0.6820 \\
Coos & 14.1 & 3479 & 0.7823 \\
Umatilla & 7.6 & 3883 & 0.2252 \\
Benton & 6.7 & 3668 & 0.3686 \\
Morrow & 5.8 & 3705 & 0.1848 \\
Gilliam & 4.9 (lowest) & 3615 & 0.0829 \\
\hline
\end{tabular}

*Source: Division of Employment, State of Oregon 
Gilliam, Morrow, Benton, and Umatilla, on the other hand, have the lowest. Column 4 contains the coefficients of correlation between unemployment rates of each of the counties and that of the state. This was done over a period of 36 months which began in January 1978 and ended December 1980. It is clear that counties with highest unemployment rates have larger coefficients of correlation while counties with low unemployment rates have smaller coefficients of correlation. What this means is that counties whose unemployment rates are strongly affected by what happens in the rest of the state have a higher rate of unemployment. Independent counties, such as Gilliam, tend to weather poor economic times well as indicated by low rates of unemployment. In contrast, counties with high unemployment rates are very heavily dependent on one industry (see Appendix C). Lumber and wood products constitute 15.03 percent of the total employment in Harney County. In Coos, Grant and Crook counties, the figures are $18.39,18.95$, and 33.08 percent, respectively. On the other hand, counties with the lowest rate of unemployment have the smallest percentage of total employment engaged in the wood industry ranging from zero for Gilliam to 6.23 percent for Benton. In addition, lumber and wood product industries in all eight counties do not seem to have a high correlation with such basic industries as trade, finance, insurance and real estate, and service. Income earned by the lumber and wood product industry is exported elsewhere without the benefit of a local multiplier effect. The high unemployment rate in the lumber and wood product industry has become a nation-wide problem triggered by soaring interest rates. In a recent article in the Oregonian, Patrick Connolly (33, p. A17) points out that "as of October 10, 1981, 51\% of 
the 102,000 western sawmill workers were either laid off or working shorter shifts. In Maine, small family owned mills that employ up to 300 workers are laying off hundreds."

These facts further support the finding that the negative relationship between diversification and unemployment results from local self-sufficiency in small economies. Furthermore, higher L.I.D. values, as shown in Table IV, Column 3, tend to correspond to lower rates of unemployment. Higher levels of industrial (or sectorial) dependence in these counties correspond to lower rates of unemployment. (A more detailed list of all measures of diversification and unemployment rates by county is shown in Table III.) The regions which are self-sufficient, including the exhibiting of a greater degree of dependence among economic sectors, tend to have a lower rate of unemployment and emerge less subject to outside forces.

In 1980 , the size of population in Oregon counties varied from a low of 1513 in the case of Wheeler county to a high of half a million in Multnomah. The question of the role of population size in economic diversification has been raised by a number of researchers. Clemente and Sturgis (1970) found that "there is a direct relationship between the size of a population and the extent of the diversification of industrial structure (34, p. 65). They claimed that 16.8 percent of the variability in diversification in the U.S. can be explained by changes in population size. Their findings have been confirmed by crowley (1973) and Paraskevopoulos (1975).

The results of stepwise regression conducted on Oregon counties and SMSA's further support the findings of clemente and Sturgis. It was 
found that 16.4 percent of changes in diversification levels in these counties could be explained by changes in population size. However, population size did not play as important a role in the changes of unemployment rates. Population size and the level of diversification were regressed against the rate of unemployment in a stepwise multiple regression model:

$$
Y_{u n}=\alpha+\beta_{1} P+\beta_{2} D
$$

Where $Y_{\text {un }}$ is the rate of unemployment

$P$ is population size and $D$ is the level of diversification.

The level of diversification was selected on the first step since it has a higher $F$ value of 11.6 compared to 5.6 for population size. The importance of diversification in explaining changes in unemployment rate is also evident by the coefficients of correlation. The coefficient of correlation between diversification and unemployment rate is -0.528 compared to -0.249 for population. The figures translate to coefficients of determinations (R $\xi$ ) of 0.278 and 0.062 respectively. This means 27 percent of the changes occurring in the rates of unemployment can be explained by diversification while only six percent of these changes are explainable by the size of population. The inclusion of population as a second variable seems to improve $R^{2}$ only by a fraction, a change from .27 to .28 as indicated in step two. One possible explanation is that diversification and population size are significantly correlated.

In addition to population, an argument can be made to include control variables for possible systematic measurement error in unemployment and the L.I.D. Two such variables are the Labor Participation Rate (LPR) and Per Capita Agricultural Income (PCAI). Table $V$ below shows the 
results of a multiple linear regression run that included LPR, PCAI, and L.I.D, as independent variables and unemployment rate as the dependent variable.

TABLE $V$

MULTIPLE LINEAR REGRESSION RESULTS

\begin{tabular}{lccccc} 
Variable & $\underline{B}$ & Std Error B & RSQ & F Value \\
\cline { 1 - 1 } LPR & 2.5362 & 5.8654 & 0.0685 & 0.187 \\
PCAI & -0.5407 & 0.2800 & 0.0338 & 3.728 \\
L.I.D. & -0.0063 & 0.0018 & 0.2709 & 12.102 \\
\hline
\end{tabular}

Level of significance $\alpha=0.05$

The three independent variables were entered in the order of LPR being first followed by PCAI and L.I.D. This ordering method was accomplished by varying the inclusion levels. The contributions of these variables in explaining changes in unemployment rate is apparent in their respective $R^{2}$ 's. Labor Participation Rate (LPR) has an $R^{2}$ of 0.0685 which means that only six percent of the changes in unemployment rate are explainable by changes in LPR. When the Per Capita Agricultural Income (PLAI) was added, this resulted in a new $R^{2}$ of 0.1023 which is four percentage points higher than the original $\mathrm{R}^{2}$. However, when the Level of Industrial Dependence (L.I.D.) was added as a third variable, $\mathrm{R}^{2}$ increased to 0.3732 which meant that 37 percent of the changes in unemployment rate can be explained by the three variables jointly. Furthermore, this increase in $R^{2}$ from 0.1023 to 0.3732 illustrates that the ability of L.I.D. to explain 27 percent of the changes in unemployment is independent of Labor Participation Rate (LPR) 
and Per Capita Agricultural Income (PCAI). The same results were also obtained by a separate regression run using stepwise regression. However, in this case L.I.D. was selected first due to its large $F$ value.

At the outset of this investigation, the stated objectives were: first, to develop a more appropriate measure of economic diversification, and second, to test the hypothesis that there is no relationship between economic diversification and regional unemployment. This investigation is not an inquiry into the causes of unemployment in Oregon. This topic could very well be the goal of another study. However, this topic cannot be dismissed without a few remarks on the complexity of regional unemployment problems. Lynn E. Browne (1978) points out that there are at least ten variables that can explain changes in regional unemployment rates. These include: national personal income, business cycle, per capita wage and salary, stock of capital equipment, ratio of capital equipment to labor, racial mix and a few others, as well. It is obvious from this list that regional unemployment is a highly complex problem. What has been presented in the course of this investigation is a look into the possible effect of economic diversification on regional unemployment. No such inquiry has ever beer conducted before. The main reason for this lack of effort is the problem of how to measure economic diversification. This problem was dealt with in earlier chapters. It is clear at this point that economic diversification does play a role in regional unemployment, but it is by no means the major factor. This finding should assist decision makers as they pursue a plan of economic diversification. 


\section{CHAPTER VI}

\section{SUMMARY, CONCLUSIONS AND RECOMMENDATIONS}

\section{Summaxy}

The role of diversification in solving economic problems has beell the topic of discussion by many scholars for the past fifty years. Both in the United States and abroad, this concept has been analyzed in terms of its relation to economic cycles, and to the more immediate problem of high unemployment.

Over the past two years, considerable attention has been focused by civic leaders on the problem of high unemployment in the State of Oregon. The percentage of joblessness continues to be higher than that of the nation. A depressed housing market, caused by high interest rates, along with an increase in the import of lanadian timber has reduced the demand for Oregon lumber and wood products drastically. This has resulted in an abnormally high unemployment rate in many of Oregon's counties which are dependent on the wood industry; for example, the 1980 jobless rate in Harney county reached a record high of 29 percent. At the other end of the spectrum, less dependent counties, such as Gilliam and Morrow, continued to grow during the same period with unemployment rates of merely 4.9 and 5.8 percent respectively. These rates are about half of the state average.

Many community leaders, including the governor, seem convinced that the only solution is economic diversification. This argument makes 
a great deal of sense at first glance. The notion is that with diversification a community becomes less vulnerable to outside forces and develops a more stable economy. What is diversification? Does a diversified economy ensure a lower rate of unemployment?

These were the basic research questions examined in this dissertation. With regard to the first question, there is no agreement on a precise definition of diversification. It is commonly acknowledged, however, that diversification is identified with a greater variety of industries in a given region.

This concern with the role of economic diversification is neither a recent phenomena nor limited to one school of thought. Tress led the way in his Ogive approach to the problem of diversification nearly fifty years ago. The basic premise is that evenly distributed employment among the industries of a given region is the ideal situation. The portfolio approach pioneered by conroy in 1973, on the other hand, claims that regions with small portfolio variances are more stable. A region's variance not only depends on the variance of each industry, but also on the covariances among them. Entropy, the third of these schools, is perhaps the least productive. This function has been borrowed from the field of thermodynamics and poorly applied in this situation. Its mathematical formulation identifies an even distribution as the ideal norm. This approach is very similar to the Ogive. In fact, when the results obtained by the Ogive were correlated with those of entropy, a rank correlation of .98 was discovered.

Because of the many shortcomings of these approaches, the first objective was to develop a new and more proper index of diversification. 
This measure seeks to explain the relationship between economic diversification and regional unemployment. The measure developed is similar to conroy's as it considers the relationship among regional industries. However, the two statistics which measure these relationships are different. This index was calculated for a total of 29 counties and three additional SMSAs in the State of Oregon in 1980. This constituted the cross-sectional study. A longitudinal study was also conducted with two specially selected counties, Morrow and Harney, from the years 1975-1980. In addition, additional measures of diversification including conroy's and the Ogive were calculated.

As the research findings indicate, the newly developed measure of diversification, L.I.D., explains in a superior manner the relationship between diversification and unemployment. There also emerged a statistically significant association between diversification and unemployment. However, only 27 percent $\left(R^{2}=.27\right)$ of the variations in the rate of unemployment became explainable by changes in the level of economic diversification.

\section{Conclusions}

Although there is a definite relationship between economic diversification and unemployment, it is not as strong as previously predicted. Therefore, this finding should be taken into consideration whenever government and business policy makers make plans to diversify. Other factors which influence unemployment more strongly than diversification include: national personal income, business cycle, stock of capital equipment, etc. 
The second conclusion is based on the type of relationship that bounds the various economic sectors of a region. In the State of Oregon, local economies with internal dependence have lower unemployment than economies which are more dependent on the rest of the nation. It has been illustrated that counties with high levels of internal dependence, such as Gilliam, Morrow and Benton have a lower rate of unemployment. An analogy can be made with a Swiss village. In such an area, the butcher, the baker, the farmer and the doctor serve the local population. The multitude of products and services do not support the production of a single export item, but serve to meet local demand. Lesser degrees of internal dependence exist in high unemployment counties, such as Harney, Crook, and Grant, which rely heavily on the single export industry of lumber and wood products.

Recommendations

The guidelines of the State of Oregon's economic development policy are specified in Chapter 184 of the Revised Statutes. The purpose of ORS 184.001 to 184.210 is to:

(a) Maintain and improve the economic base of the state;

(b) Diversify the economic base of the state;

(c) Expand international trade;

(d) Assist the economically lagging areas in the state; and

(e) Accomplish these purposes in a way that complies with all local, state and federal regulations relating to environmental quality. 
To accomplish these goals, the Department of Economic Development has initiated a number of programs in the areas of business development, community economic development, ports, international trade, and industrial development. In the latter case, industrial revenue bonds have been used to help finance new plants or expand already established ones. The State of Oregon should continue its support of efforts to diversify rural counties and those with current dependence on the lumber industry. These efforts will further be enhanced, if, first, the new industries are selected on the basis of contribution to the economic dependency as defined by the L.I.D. index. Therefore, the new firm should not be an export oriented company. The products should serve a well-diversified market and local customers. Items produced by this firm should be in demand by different industries and consumers in various regions.

While this investigation was conducted in the State of Oregon, which possesses a large number of rural counties, it is quite likely that the L.I.D. model can be used in more urban and larger states. It will be the task of future researchers to test the model. 


\section{A SELECTED BI BLIOGRAPHY}

1. Atiyeh, Vic. "The State of Oregon Economy." A speech before the Eugene and Springfield Chambers of Commerce and Lane County Department of Employment. February 5, 1981.

2. Bahl, Roy W; Robert Firestine; and Donald Phares. "Industrial Diversity in Urban Areas: Alternative Measures and Intermetropolitan Comparisons." Economic Geography, 47, July 1971: pp. 414-425.

3. B arth, James; John Kraft; and Philip Wiest. "A Portfolio Theoretic Approach to Industrial Diversification and Regional Employment." Journal of Regional Science, Vol. 15, No. 1, 1975: pp. $9-15$.

4. Conkling, Edgar C. "South Wales: A Case Study in Industrial Diversification." Economic Geography, Vol. 39, No. 3, July 1963: pp. 258-272.

5. Conroy, Michaei E. "Alternative Strategies for Regional Industrial Diversification." Journal of Regional Science, Vol. 15, No. 1, April 1974: pp. 36-51.

6. - "The Concept and Measurement of Regional Industrial Diversification." Southern Economic Joumal, January 1975: pp. 492-505.

7. 1 Praeger, 1975. Regional Economic Diversification. New York:

8. Crowley, Ronald W. "Reflections and Further Evidence on Population Size and Industrial Diversification." Urban Studies, Vo1. 10, No. 2, February 1973: pp. 91-94.

9. Federman, Stan. "Economic Opposites," The Oregonian, November 30 , 1980: p. 1 .

10. Gratton, Chris. "Industrial Diversification in New Towns." Urban Studies, Vol. 6, No. 2, July 1979: pp. 155-163.

11. Hackbart, Merlin M. and Donald A. Anderson. "On Measuring Economic Diversification." Land Economics, 4, November 1975: pp. 374-378.

12. Jaep, William F. Encyclopedia of Science and Technology, New York: McGraw-Hil1, 1977: pp. 9-10. 
13. Markowitz, Harry. "Portfolio Selection." The Journal of Finance, 7, 1952: pp. 77-91.

14. McLaughlin, Glenn. "Industrial Diversification in American Cities." Quarterly Journal of Economics, 44, November 1930: pp. $131-149$.

15. Parr, John B. "Specializatinn, Diversification and Regional Development." Professional Geographer, Vol. XVII, No. 6, 1965: pp. $21-25$.

16. Rodgers, Allen. "Some Aspects of Industrial Diversification in the United States." Economic Geography, January 1957: pp. $16-30$.

17. Rosen, Richard. "Identifying States and Areas Prone to High Unemployment." Monthly Labor Review, March 1980: pp. 20-24.

18. Shannon, C.E. "A Mathematical Theory of Communication." Be11 System Technological Journal, Vo1. 27, 1948: pp. 397-423, 623-656.

19. Sharpe, W.F. Portfolio Theory and Capital Market. New York: McGraw-Hi11, 1970 .

20. Shear, James A. "A General Measure of Diversity." Professional Geographer, Vo1. XVII, No. 2, March 1965: pp. 14-17.

21. St. Louis, Larry V. "A Measure of Regional Diversification and Efficiency." The Annal of Regional Science, Vo1. XIV, No. 1, March 1980: pp. 21-31.

22. Sykes, J. "Diversification of Industry." Economic Journal, Vol. 60,1950 : pp. 697-714.

23. Taylor, J. "A Note on the Definition of Industrial Diversification." Journal of Economic Studies, Vol. 2, 1967: pp. $105-114$.

24. Tobin, J. "Liquidity Preference as Behavior Towards Risk." Review of Economic Studies, Vol. 25, 1958: pp. 65-85.

25. Tress, R.C. "Unemployment and the Diversification of Industry." The Manchester School, 9, 1938: pp. 14-17.

26. Ullman, Edward L. and Michael F. Dacey. "The Minimum Requirements Approach to the Urban Economic Base." Papers and Proceedings of the Regional Science Association, 6, 1960: pp. 175-194.

27. U.S. Department of Commerce, Bureau of the Census. The Fourteenth Census of the United States, Vol. IX, Manufactures, 1920: p. 7 . 
28. Wasylenko, Michael J. and Rodney A. Erickson. "On Measuring Economic Diversification." Land Economics, 54, February 1978: pp. 106-109.

29. Yamane, Taro. Statistics, An Introductory Analysis. New York: Harper and Row Publishers, 1967.

30. U.S. Department of Labor, Bureau of Labor Statistics. BLS Handbook of Methods. Bullet in 1910, Washington, D.C., 1976 .

31. Kimble, Gregory A. How to Use and Misuse Statistics. Englewood Cliffs, New Jersey: Prentice-Hall, Inc., 1978.

32. Netter, J. and $W$. Wasserman. Applied Linear Statistical Models. Homewood, Illinois: Richard D. Irwin, Inc., 1974.

33. Connolly, Patrick. The Oregonian, October 20, 1981: p. A17.

34. Clemente, Frand and Richard B. Sturgis. "Population Size and Industrial Diversification." Urban Studies, Vo1. 8, 1971: pp. $65-68$.

35. Brown, Lynn E. "Regional Unemployment Rates -- Why Are They So Different?" New England Economic Review, July/August 1978: pp. 5-26.

36. Florence, Sargent P. Investment, Location and Size of Plant. lambridge: Oxford University Press, 1948.

37. Stinson, John. U.S. Department of Labor, Bureau of Labor Statistics. How the Government Measures Unemployment. Report 505, Washington, D.C., 1977.

38. Kelejian, H. and W. Oates. Introduction to Econometrics. New York: Harper and Row, 1974.

39. Crowley, Ronald W. "Reflections and Further Evidence on Population Size and Industrial Diversification." Urban Studies, Vol. 10, 1973: pp. 91-94.

40. Paraskevopoulos, Chritos C. "Population Size and the Extent of Industrial Diversification: An Altemative View." Urban Studies, Vol. 12, 1975: pp. 105-107.

41. Nie, Norman, et al. Statistical Package for the Social Sciences. New York: McGraw Hill, 1975. 
RELATED REFERENCES

Books

Allen, R.G.D. Index Numbers in Theory and Practice. Chicago: Aldin Publishing Company, 1975.

Brown, A.J. and E.M. Burrows. Regional Economic Problems. George Allen and Urwin, 1977.

Clorck, Gordon L. A Simple Model of Regional Stagnation. Harvard University Press, 1978.

Draper, N. and H. Smith. Applied Regression Analysis, Second Edition, New York: John Wiley \& Sons, 1981.

Durand, John D. The Labor Force in Economic Development. Princeton University Press, 1975.

Holland, Stuart. The Regional Problem. New York: St. Martin Press, 1976.

Kendall, Maurice G. Rank Correlation Methods. London: Griffin and Company, 1970.

Levin, Melvin R. Community and Regional Planning: Issues in Public Policy. Third Edition. New York: Praeger, 1977.

Mishan, Ezra J. The lost of Economic Growth. New York: Praeger, 1967.

Pindyck, R.S. and D.L. Rubinfeid. Econometric Models and Economic Forecasts. New York: McGraw-Hill, 1976.

Prescott, James R. and Cris W. Lewis. Urban-Regional Economic Growth Policy. Ann Arbor Science Publishers, 1975.

Samples, James C. Patterns of Regional Economic Change: A Quantitative Analysis of U.S. Regional Growth and Development. Cambridge, Mass.: Ballinger, 1974.

Thorndike, Robert M. Correlational Procedures for Research. New York: Gardner Press, 1978.

Usher, Dan. The Measurement of Economic Growth. New York: Columbia University Press, 1980 . 
Wilson, A.G. Entropy in Urban and Regional Modelling. London: Pion Ltd., 1970.

\section{Employment-Unemp loyment}

Bowers, Norman. "Probing the Issue of Unemployment Duration." Monthly Labor Review, Vol. 103, No. 3, March 1980.

DeRooy, Jacob. "Analysis of Public Employment Impact Multipliers in Depressed Areas." Growth and Change, Vol. II, No. 2, 1980.

Hellman, Daryl A. "The Spatial Distribution of Unemployment by Occupation: A Further Note." Journal of Regional Science, Vol. 13, No. 3, December 1973.

Hyclak, Thomas and Gerald Lynch. "An Empirical Analysis of State Unemployment Rates in the 70's." Journal of Regional Science, Vol. 20, No. 3, August 1980 .

Jeffrey, D. "Regional Fluctuation in Unemployment Within the U.S. Urban Economic System: A Study of the Spatial Impact of Short Term Economic Change." Economic Geography, Vol. 52, No. 2, April 1974.

Leon, C.B: and P.L. Rones. "Employment and Unemployment During 1979: An Analysis." Monthly Labor Review, Vol. 103, No. 2, February 1980.

Little, Roger D. and E.E. Liebhafsky. "Analysis of Changing Employment Opportunity by Occupational Group." Growth and Change, Vol. 11, No. 1, January 1980.

Moriarty, Barry M. "The Distributed Lag Between Metropolitan Area Employment and Population Growth." Journal of Regional Science, Vol. 16, No. 2, August 1976.

Nilsen, Rigurd R. "Metropolitan and Non-metropolitan: Effect of Self Employment Bias on Unemployment Rate." Growth and Change, Vol. 11, No. 4, October 1980 .

Public Policy

Haverman, Robert H. "Evaluating the Impact of Public Policies on Regional Welfare." Regional Studies, Vo1. 10, No. 4, 1976.

Fahle, Vernon L. and Robert M. Rauner. "Priorities and Allocations: National Policy for Regional Economic Development." Growth and Change, Vol. 2, No. 4, October 1975. 
Malizia, Emil and Dianne Reid. "Perspectives and Strategies for U.S. Regional Development." Growth and Change, Vol. 7, No. 4, October 1976.

Martin, Randolph L. "Legislation Versus Administration: An Empirical Note on Federal Regional Development Programs." Growth and Change, Vol. 10, No. 2, April 1979.

Mlemyk, William H. "An Evaluation: The Tools of Regional Development Policy." Growth and Change, Vol. 11, No. 2, April 1980.

Government Documents

Mason, Bob. Annual Economic Report 1979 Harney lounty. State of Oregon, Employment Division, Department of Fuman Resources, 1979.

State of Oregon, Employment Division. Oregon Covered Employment and Payrolls 1977. Salem, Oregon 1979 .

State of Oregon, Employment Division, Occupational Profiles of Oregon's Manufacturing Industries 1977. Salem, 1979 .

Stewart, Roland G. Annual Economic Report 1979 Morrow County. State of Oregon, Employment Division, Department of Human Resources, 1979.

U.S. Department of commerce, Bureau of the Census. County Business Patterns 1978 Oregon. CBP78-39, Washington, D.C.: Government Printing Office, August 1980.

U.S: Department of Labor, Bureau of Labor Statistics. Employment and Earnings, 1939-78. Bulletin 1370-13, v ashington, D.C.: Government Printing Office, 1979.

- Geographic Profile of Employment and Unemployment 1979. Report No. 619, Washington, D.C.: Government Printing Office, December 1980 .

- Handbook of Labor Statistics. Bulletin 2070, Washington, D.C.: Government Printing Office, December, 1980.

- Birectory of Occupational Wage Surveys 1974-79. Report 606, Washington, D.C.: Government Printing Office, September 1980.

U.S., Executive Office of the President, Office of Management and Budget. Standard Industrial Classification Manual 1972. Washington, D.C.: Government Printing Office, 1972 . 
APPENDIX A

CROSS-SECTIONAL STUDY 
The following are four exhibits illustrating the output obtained by S.P.S.S. of four regression runs using the four measures of economic diversification as independent variables and the rate of unemployment as the dependent variable. Exhibit 1, illustrates the results obtained by using Florence's measure as the independent variable in a simple linear regression model. Exhibit 2 indicates the results obtained by the use of the ogive measure of diversification. Exhibit 3 shows Conroy's measure of diversification as the independent variable while Exhibit 4 indicates the results obtained by using the L.I.D. measure of diversification. 


\section{EXHIBIT 1}

FLORENCE MEASURE AS INDEPENDENT VARIABLE

deptruent VARIAGLE. PCtun

TARIAOLE(S) ENIERED OH SIFP NUMAFA 1. ILNORM

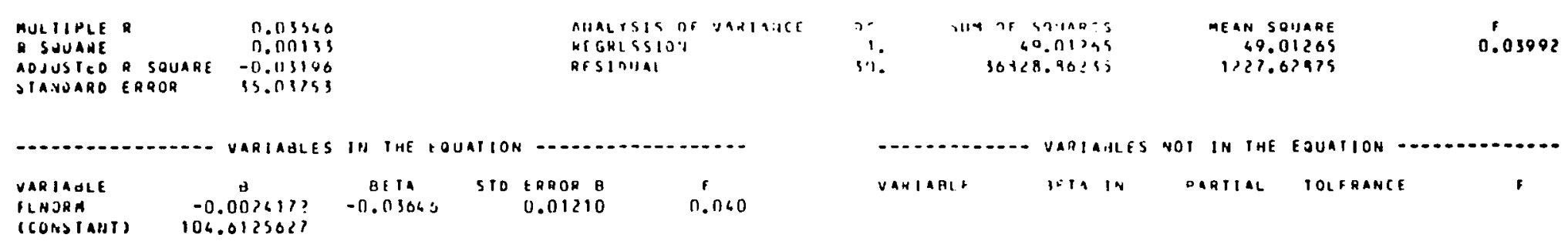

MARIMUA SIEP REACHEO

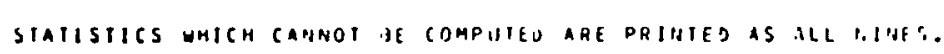

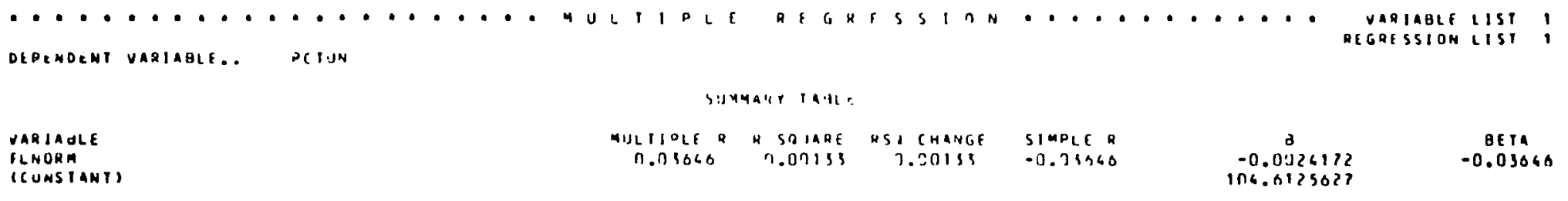




\section{EXHIBIT 2}

OGIVE MEASURES AS INDEPENDENT VARIABLE

\section{DEPEXOENT VARIAGLF.. PC TIII}

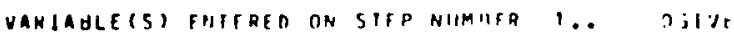

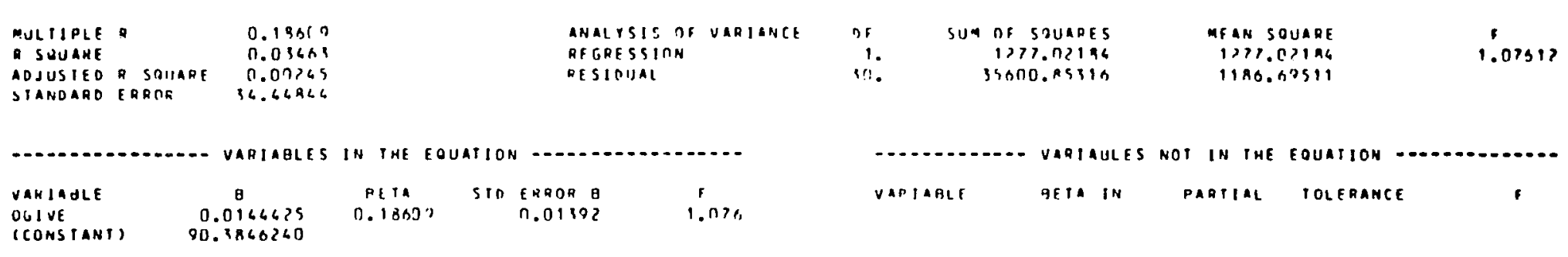

MAXIAUN SIEP REACHED

STATISTICS HHICH CANNOT tE COMPUTEO ARF PRIVIED AS ALL HINHS.

\begin{tabular}{|c|c|c|c|c|c|c|c|}
\hline \multicolumn{8}{|c|}{ SUMAMARY TAHLF } \\
\hline $\begin{array}{l}\text { VARIABLE } \\
\text { OLIVE } \\
\text { (CONSTANT) }\end{array}$ & & $\begin{array}{c}\text { MUL YPLE } \\
0.19600\end{array}$ & $\begin{array}{l}0 \text { SOU18E } \\
0.03633\end{array}$ & $\begin{array}{c}\text { Den CHANGEF } \\
\text { C.MPGQ }\end{array}$ & $\begin{array}{l}\text { SIYPLE D } \\
\text { O.1ASD? }\end{array}$ & $\begin{array}{c}\text { p } \\
0.0146625 \\
90.31466260\end{array}$ & $\begin{array}{l}\text { AFin } \\
0.18300\end{array}$ \\
\hline
\end{tabular}




\title{
EXHIBIT 3
}

CONROY MEASURE AS INDEPENDENT VARIABLE

\begin{abstract}
DEPENOENT VARIAHEF.. PTTIM
\end{abstract}

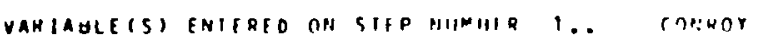

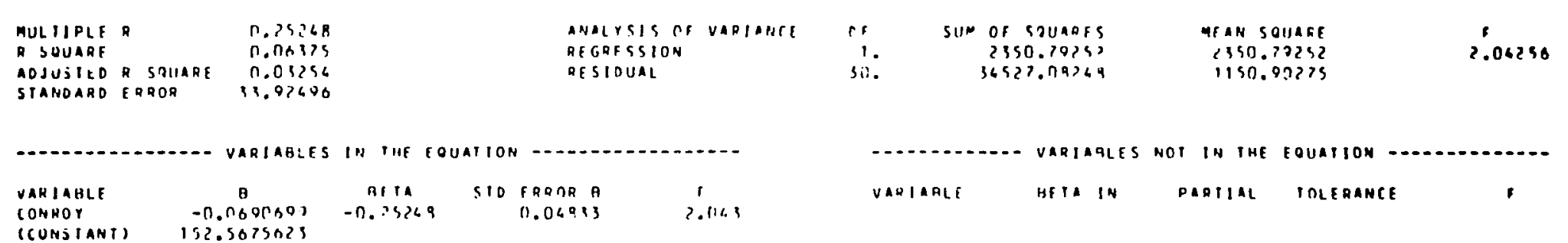

MAXINU.A SIEP REACHED

STAIISIICS UHICI CANNOT JE COMPUIER ARE PRINICD AS ALL HINF:.

\begin{tabular}{|c|c|c|c|c|c|c|c|}
\hline \multicolumn{8}{|c|}{ surimant IA.ll F } \\
\hline $\begin{array}{l}\text { VARIAQLLC } \\
\text { CONROP } \\
\text { COONSTANTI) }\end{array}$ & & $\begin{array}{c}\text { MUE PlPLE } \\
\text { n.2536P }\end{array}$ & $\begin{array}{l}r \text { sollaur } \\
\text { rensizes }\end{array}$ & $\begin{array}{c}\text { Asia craporis } \\
\text { r.nas?s }\end{array}$ & $\begin{array}{l}\operatorname{simplf}= \\
-r .25>46\end{array}$ & $\begin{array}{c}\text { P } \\
-n .0390640 \\
157.5615073\end{array}$ & $\begin{array}{c}\text { BEIA } \\
-0.25268\end{array}$ \\
\hline
\end{tabular}


EXHIBIT 4

L.I.D. AS INDEPENDENT VARIABLE

DEPENDENT VARIABLE.. PCTISN

VARIAOLE(S) FNITHEO ON SIFP NIITHER 1 .. LIO

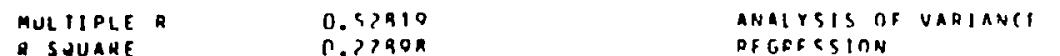

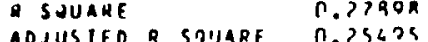

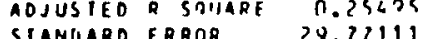

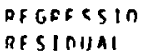

DA. Slly Co solianis

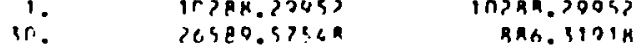

MEAN SOUAFE

InsRa. 2005?

11.30190

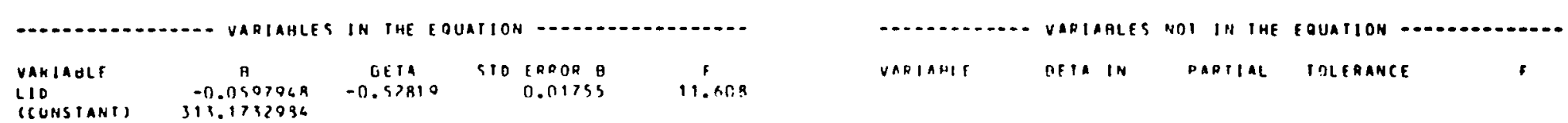

(CUNSIANT) 319.1732934

MAXINUA STEP REACHEO

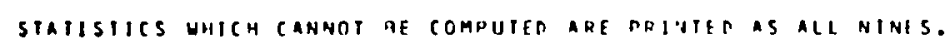

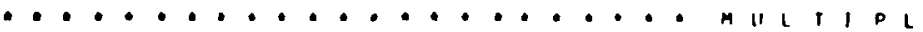

VARIABLE LIST

DEPENDENT VARIAaLE.. DCTUN

egaression List

VARIADLF

LIO

SUMmant tanLe

(CONSIANT)

\begin{tabular}{|c|c|c|c|c|c|}
\hline $\begin{array}{c}\text { MILLITLF }{ }^{R} \\
0.52310^{\circ}\end{array}$ & $\begin{array}{l}\text { R SJIIAPE } \\
0.27908\end{array}$ & $\begin{array}{c}\text { RSO CHAMTEE } \\
\text { C.?7A9A }\end{array}$ & $\begin{array}{l}\text { S1MPLE R } \\
-0.52919\end{array}$ & $\begin{array}{c}\theta \\
-0.0587068 \\
319.1737986\end{array}$ & $\begin{array}{c}\text { OEIA } \\
-0.32810\end{array}$ \\
\hline
\end{tabular}


APPENDIX B

LONGITUDINAL STUDY 
Exhibits 5 and 6 are computer outputs using S.P.S.S. of two regression runs dealing with the L.I.D. measure of diversification (of Morrow and Harney counties) and its relationship to the rate of unemployment for the period 1975 to 1980. 
EXHIBIT 5

MORROW COUNTY REGRESSION

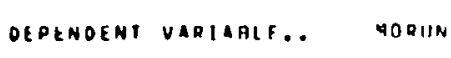

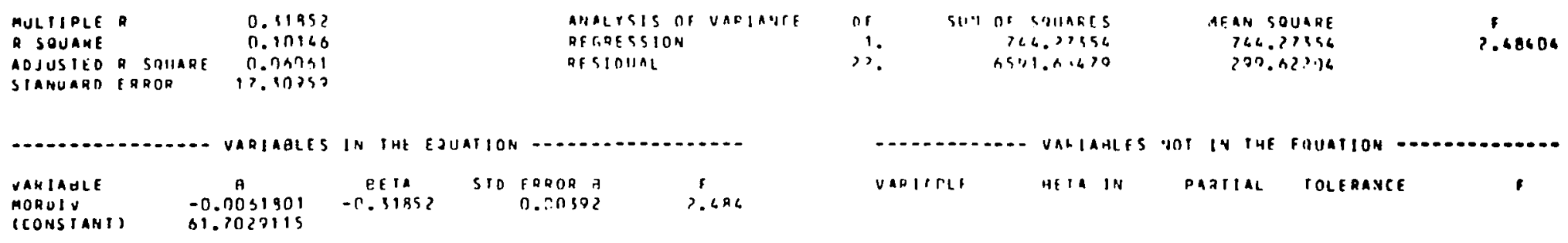

MAXIKUM SIEP REACHEO

SIATISIICS MHICH CANNOT IE COMDUTRO ARE DRINIFD AS ALL NINGS.

\begin{tabular}{|c|c|c|c|c|c|c|c|}
\hline \multicolumn{8}{|c|}{ SUAMER TAOLLF } \\
\hline $\begin{array}{l}\text { VARIAALE } \\
\text { MOKOIL } \\
\text { (CONSTANT) }\end{array}$ & & $\begin{array}{c}\text { YIILIIPLE } \\
\text { C. X19.5? }\end{array}$ & $\begin{array}{l}\text { B SnUAR: } \\
\text { r.lnice }\end{array}$ & 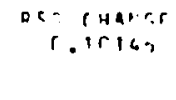 & $\begin{array}{l}=1110180 \\
-11.1195\end{array}$ & $\begin{array}{c}4 \\
-0.0031901 \\
31.7020115\end{array}$ & $\begin{array}{c}\text { RE IA } \\
-0.31552\end{array}$ \\
\hline
\end{tabular}




\section{EXHIBIT 6}

HARNEY COUNTY REGRESSION AND DURBIN-WATSON TEST FOR HARNEY AND MORROW

DEPE:HOENT VARIAGLE.. HARIH

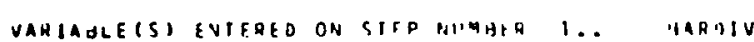

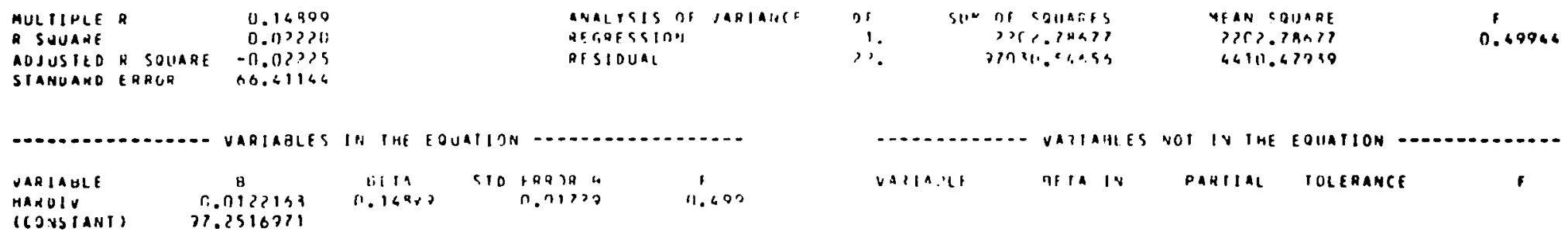

MAXINUAS SIEP REACHEO

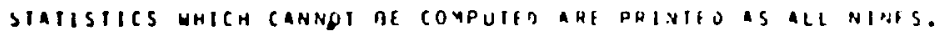

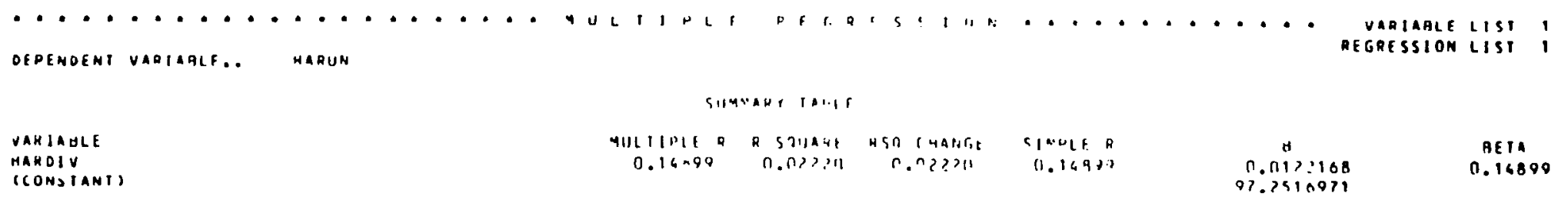

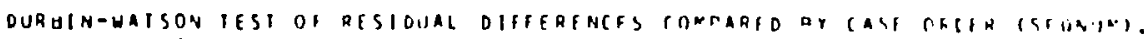

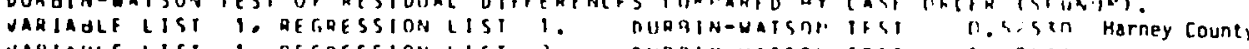

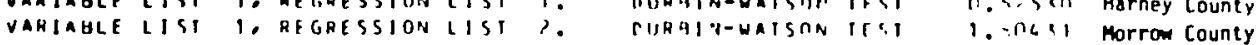


APPENDIX C 
Matrices 1 through 8 illustrate the coefficient of correlation among ten industries and the percentage of employment in each industry for eight selected counties. Gilliam County, for example, is highly independent of what happens in the rest of the state. Harney County, on the other hand, is very much affected by economic conditions in the state as a whole. 
MATRIX 1

COEFFICIENTS OF CORRELATION AND PERCENT EMPLOYMENT HARNEY COUNTY, 1980

\begin{tabular}{|c|c|c|c|c|c|c|c|c|c|c|c|}
\hline ज. & \multicolumn{10}{|c|}{ INDUSTRIES } & \multirow{2}{*}{$\%$} \\
\hline 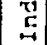 & 1 & 2 & 3 & 4 & 5 & 6 & 7 & 8 & 9 & 10 & \\
\hline 1 & 1.0000 & & & & & & & & & & 15.03 \\
\hline 2 & N.A. & 1.0000 & & & & & & & & & 0 \\
\hline 3 & N.A. & N.A. & 1.0000 & & & & & & & & 0 \\
\hline 4 & N.A. & N.A. & N.A. & 1.0000 & & & & & & & 0 \\
\hline 5 & -0.6720 & N.A. & N.A. & N.A. & 1.0000 & & & & & & 7.08 \\
\hline 6 & -0.1716 & N.A. & N.A. & N.A. & 0.1006 & 1.0000 & & & & & 3.97 \\
\hline 7 & -0.3496 & N.A. & N.A. & N.A. & 0.5911 & 0.2225 & 1.0000 & & & & 23.02 \\
\hline $\mathbf{a}$ & N.A. & N.A. & N.A. & N.A. & N.A. & N.A. & N.A. & 1.0000 & & & 3.10 \\
\hline 9 & 0.2628 & N.A. & N.A. & N.A. & 0.0876 & -0.3627 & 0.7020 & N.A. & 1.0000 & & 12.05 \\
\hline 10 & $-0.621 \gamma$ & N.A. & N.A. & N.A. & 0.6856 & 0.2079 & 0.6405 & N.A. & 0.0812 & 1.0000 & 36.75 \\
\hline
\end{tabular}

- 1 - Lunber t mood 2 - Other Durable coods 3 - Food Products 1 - Other Non-Durable Goode

5 - Construction 6 - Transportation. Communications butllitles 7 - Trade $B$ - Finance,

Insurance, 6 Real Estate 9 - Services 10 - Government N.A. - Not Avallable

-. percent of total Employment 
MATRIX 2

COEFFICIENTS OF CORRELATION AND PERCENT EMPLOYMENT CROOK COUNTY, 1980

\begin{tabular}{|c|c|c|c|c|c|c|c|c|c|c|c|}
\hline \multirow{2}{*}{ 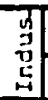 } & \multicolumn{10}{|c|}{ INDUSTRIES } & \multirow{2}{*}{$\%$} \\
\hline & 11 & 2 & 3 & 4 & 5 & 6 & 7 & 8 & 9 & 10 & \\
\hline 1 & 1.0000 & & & & & & & & & & 33.08 \\
\hline 2 & N.A. & N.A. & & & & & & & & & 0 \\
\hline 3 & N.A. & N.A. & N.A. & & & & & & & & 0 \\
\hline 4 & N.A. & N.A. & N.A. & N.A. & & & & & & & o \\
\hline 5 & -0.2482 & N.A. & N.A. & N.A. & 1.0000 & & & & & & 2.62 \\
\hline 6 & 0.0369 & N.A. & N.A. & N.A. & -0.0413 & 1.0000 & & & & & 2.89 \\
\hline 7 & 0.0861 & N.A. & N.A. & N.A. & -0.5693 & -0.2965 & 1.0000 & & & & 21.00 \\
\hline 8 & 0.5725 & N.A. & N.A. & N.A. & -0.0746 & 0.2852 & -0.0263 & 1.0000 & & & 2.62 \\
\hline 9 & -0.1657 & N.A. & N.A. & N.A. & 0.3893 & 0.6474 & -0.4939 & 0.2317 & 1.0000 & & 14.16 \\
\hline 10 & -0.7282 & N.A. & N.A. & N.A. & 0.3662 & 0.1861 & -0.2592 & -0.2474 & 0.5127 & 1.0000 & 23.63 \\
\hline
\end{tabular}

1. Lumber thood 2 - Other Durable Coods 3 - Food Products 1 - Other Non-Durable Goods

5 - Conntruction 6 - Transportation, Communlcations c Utllities 7 - Trade 8 - Finance,

Insurance, Real Estate 9 - Services 10 - Government N.A. - Not Avallable

- Porcent of Total Employment 


\section{MATRIX 3}

COEFFICIENTS OF CORRELATION AND PERCENT EMPLOYMENT GRANT COUNTY, 1980

\begin{tabular}{|c|c|c|c|c|c|c|c|c|c|c|c|}
\hline 3 & & & & & INDUS & It:S & & & & & \\
\hline 量 & 1 & 2 & 3 & 4 & 5 & 6 & 7 & 8 & 9 & 10 & $\%$ \\
\hline 1 & 1.0000 & & & & & & & & & & 18.95 \\
\hline 2 & N.A. & 1.0000 & & & & & & & & & 0 \\
\hline 3 & N.A. & N.A. & 1.0000 & & & & & & & & 0.87 \\
\hline 4 & -0.4015 & N.A. & N.A. & 1.0000 & & & & & & & 0.87 \\
\hline 5 & -0.7983 & N.A. & N.A & -0.1302 & 1.0000 & & & & & & 1.31 \\
\hline 6 & -0.5943 & N.A. & N.A. & 0.3015 & 0.5103 & 1.0000 & & & & & 3.51 \\
\hline 7 & -0.3983 & N.A. & N.A. & 0.0747 & 0.4183 & 0.1127 & 1.0000 & & & & 17.63 \\
\hline 8 & N.A. & N.A. & N.A. & N.A. & N.A. & N.A. & N.A. & 1.0000 & & & 3.07 \\
\hline 9 & -0.5016 & N.A. & N.A. & N.A. & 0.6303 & 0.5180 & 0.2685 & N.A. & 1.0000 & & 9.24 \\
\hline 10 & -0.7734 & N.A. & N.A. & 0.0783 & 0.8508 & 0.4720 & 0.7049 & N.A. & 0.7303 & 1.0000 & 44.55 \\
\hline
\end{tabular}

1 - Lumber w Wood 2 - Other Durable coods 3 - Food Products 4 - Other Non-Durable Coode

5- Construction 6 - Transportation, Communications - Utilities 7 - Trade $\theta$ - Finance,

Insurance, t Real Estate 9 - Services 10 - Covernment N.A. - Hot Avallable

* Percent of Total Employment 


\section{MATRIX 4}

COEFFICIENTS OF CORRELATION AND PERCENT EMPLOYMENT COOS COUNTY, 1980

\begin{tabular}{|c|c|c|c|c|c|c|c|c|c|c|c|}
\hline בป & & & & & INDUS & It:S & & & & & $0 /$ \\
\hline$\underset{4}{4}$ & 11 & 2 & 3 & 4 & 5 & 6 & 7 & $\theta$ & 9 & 10 & $\% 0^{\circ}$ \\
\hline 1 & 1.0000 & & & & & & & & & & 18.39 \\
\hline 2 & 0.5336 & 1.0000 & & & & & & & & & 1.24 \\
\hline 3 & 0.5910 & 0.7554 & 1.0000 & & & & & & & & 2.48 \\
\hline 4 & 0.1547 & 0.6065 & 0.5055 & 1.0000 & & & & & & & 1.97 \\
\hline 5 & 0.6845 & 0.4235 & 0.5388 & -0.0693 & 1.0000 & & & & & & 3.52 \\
\hline 6 & 0.6123 & 0.3998 & 0.5134 & 0.2214 & 0.5933 & 1.0000 & & & & & 8.48 \\
\hline 7 & 0.5023 & 0.8177 & 0.5656 & 0.6167 & 0.3900 & 0.4502 & 1.0000 & & & & 20.66 \\
\hline $\mathbf{\theta}$ & 0.6045 & 0.9303 & 0.8125 & 0.6143 & 0.6311 & 0.5636 & 0.7794 & 1.0000 & & & 4.50 \\
\hline 9 & 0.3749 & 0.8209 & 0.6862 & 0.8137 & 0.2555 & 0.4805 & 0.7533 & 0.8644 & 1.0000 & & 14.86 \\
\hline 10 & 0.2162 & -0.0520 & -0.2810 & -0.5464 & 0.2570 & 0.1074 & 0.0593 & -0.1402 & -0.4696 & 1.0000 & 23.90 \\
\hline
\end{tabular}

-1 - Lumber thood 2 - Other Durable Cooda 3 - Food Products 1 - Other Non-Durable Coode 5 - Construction 6 - Transportation, Communications w Utilities 7 - Trade 8 - Finance, Insurance, Real Estate 9 - Services 10 - Government N.A. - Not Avallable

-. Porcent of Total Employment 


\section{MATRIX 5}

COEFFICIENTS OF CORRELATION AND PERCENT EMPLOYMENT UMATILLA COUNTY, 1980

\begin{tabular}{|c|c|c|c|c|c|c|c|c|c|c|c|}
\hline ป & & & & & INUUS & HIt:S & & & & & \\
\hline 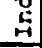 & 1 & 2 & 3 & 4 & 5 & 6 & 7 & 8 & 9 & 10 & $\%$ \\
\hline 1 & 1.0000 & & & & & & & & & & 2.86 \\
\hline 2 & 0.5764 & 1.0000 & & & & & & & & & 3.31 \\
\hline 3 & 0.1316 & 0.0152 & 1.0000 & & & & & & & & 12.04 \\
\hline 4 & 0.3812 & 0.5591 & 0.2219 & 1.0000 & & & & & & & 2.86 \\
\hline 5 & -0.0489 & 0.4238 & -0.3083 & 0.2079 & 1.0000 & & & & & & 3.11 \\
\hline 6 & 0.2748 & 0.2262 & 0.5620 & 0.5096 & N.A. & 1.0000 & & & & & 8.01 \\
\hline 7 & 0.0174 & -0.0991 & 0.6542 & 0.0636 & -0.5617 & 0.6480 & 1.0000 & & & & 25.22 \\
\hline 8 & 0.2164 & -0.0069 & 0.4086 & 0.2740 & -0.1253 & 0.6795 & 0.6472 & 1.0000 & & & 4.03 \\
\hline 9 & -0.2899 & -0.4609 & 0.3866 & -0.6318 & -0.4304 & -0.2646 & 0.3698 & 0.0160 & 1.0000 & & 14.80 \\
\hline 10 & -0.1256 & 0.3972 & 0.1099 & 0.0777 & 0.2219 & -0.4120 & -0.2902 & -0.2284 & 0.1326 & 1.0000 & 23.76 \\
\hline
\end{tabular}

- 1 - Lumber wood 2 - Other Durable Coods 3 - Food Products 1 - Other Non-Durable Coods

- Constiuction 6 - Transportation, Comnunications b Utillties 7 - Trade 8 - Flnance,

Insurance, t Real Estate 9 - Services 10 - Government N.A. - Hot Avallable

- Pexcent of Tolal kimployment 


\section{MATRIX 6}

COEFFICIENTS OF CORRELATION AND PERCENT EMPLOYMENT BENTON COUNTY, 1980

\begin{tabular}{|c|c|c|c|c|c|c|c|c|c|c|c|}
\hline \multirow{2}{*}{$\begin{array}{l}4 \\
3 \\
0 \\
\end{array}$} & \multicolumn{10}{|c|}{ INDUSTRIES } & \multirow{2}{*}{$\%$} \\
\hline & 1 & 2 & 3 & 4 & 5 & 6 & 7 & 8 & 9 & 10 & \\
\hline 1 & 1.0000 & & & & & & & & & & 6.23 \\
\hline 2 & 0.0637 & 1.0000 & & & & & & & & & 7.34 \\
\hline 3 & -0.1409 & 0.0930 & 1.0000 & & & & & & & & 0.37 \\
\hline 4 & -0.6743 & 0.3810 & 0.1914 & 1.0000 & & & & & & & 1.25 \\
\hline 5 & 0.0679 & 0.3492 & 0.2373 & -0.0423 & 1.0000 & & & & & & 1.99 \\
\hline 6 & 0.5623 & -0.0067 & 0.2331 & -0.6819 & 0.3289 & 1.0000 & & & & & 3.12 \\
\hline 7 & 0.2949 & -0.3658 & -0.6168 & -0.5164 & -0.6653 & -0.0342 & 1.0000 & & & & 17.48 \\
\hline 8 & -0.5177 & 0.3453 & 0.5369 & 0.7491 & -0.1404 & -0.2956 & -0.5069 & 1.0000 & & & 3.90 \\
\hline 9 & 0.3493 & -0.3478 & -0.3065 & -0.4861 & -0.7558 & 0.2143 & 0.7490 & -0.2253 & 1.0000 & & 16.32 \\
\hline 10 & 0.1417 & -0.5648 & -0.3924 & -0.4799 & -0.7709 & 0.0641 & 0.8919 & -0.3758 & 0.8538 & 1.0000 & 42.00 \\
\hline
\end{tabular}

1 - Lumber t Wood 2 - Other Durable Coods 3 - Food Products 4 - Other Non-Durable Goods

5 - Construction 6 - Transportation, Communications Utilitles 7 - Trade 8 - Finance,

Insurance, Real Estate 9 - Services 10 - Covernment N.A. - Not Avallablo

-. Porcent of Total Exployment 
MATRIX 7

COEFFICIENTS OF CORRELATION AND PERCENT EMPLOYMENT MORROW COUNTY, 1980

\begin{tabular}{|c|c|c|c|c|c|c|c|c|c|c|c|}
\hline \multirow{2}{*}{ 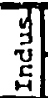 } & \multicolumn{10}{|c|}{ INDUSTRIES } & \multirow{2}{*}{$\%$} \\
\hline & 1 & 2 & 3 & 1 & 5 & 6 & 7 & $\theta$ & 9 & 10 & \\
\hline 1 & 1.0000 & & & & & & & & & & 5.96 \\
\hline 2 & N.A. & 1.0000 & & & & & & & & & 0 \\
\hline 3 & -0.3691 & H.A. & 1.0000 & & & & & & & & 21.34 \\
\hline 4 & 0.7778 & N.A. & -0.5817 & 1.0000 & & & & & & & 0.63 \\
\hline 5 & -0.5912 & N.A. & 0.6586 & -0.5373 & 1.0000 & & & & & & 26.34 \\
\hline 6 & 0.1777 & N.A. & -0.1723 & 0.4146 & -0.2199 & 1.0000 & & & & & 7.84 \\
\hline 7 & 0.2950 & N.A. & -0.4313 & 0.3835 & -0.3041 & $\because 0.1782$ & 1.0000 & & & & 11.60 \\
\hline 8 & 0.1741 & N.A. & -0.3887 & 0.5222 & -0.1803 & 0.1547 & 0.2619 & 1.0000 & & & 2.18 \\
\hline 9 & -0.3369 & N.A. & 0.2165 & -0.2526 & 0.6782 & -0.2095 & -0.0149 & 0.0440 & 1.0000 & & 6.57 \\
\hline 10 & -0.0551 & N.A. & 0.4521 & -0.2757 & -0.0788 & -0.0098 & -0.0342 & -0.3743 & -0.2646 & 1.0000 & 17.54 \\
\hline
\end{tabular}

-1 - Lumber w Hood 2 - Other Durable Coods 3 - Food Products 1 - Other Non-Durable Goods

5 - Construction 6 - Transportation, Communications + Utllities 7 - Trade B - Finance,

Insurance, - Real Estate 9 - Services 10 - Covernment N.A. - Not Avallable

- Percent of Total Employment 
MATRIX 8

COEFFICIENTS OF CORRELATION AND PERCENT EMPLOYMENT GILLIAM COUNTY, 1980

\begin{tabular}{|c|c|c|c|c|c|c|c|c|c|c|c|}
\hline \multirow{2}{*}{ 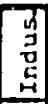 } & \multicolumn{10}{|c|}{ INDUSTRIES } & \multirow{2}{*}{$\%$} \\
\hline & 1 & 2 & 3 & 4 & 5 & 6 & 7 & $\theta$ & 9 & 10 & \\
\hline 1 & N.A. & & & & & & & & & & 0 \\
\hline 2 & N.A. & N.A. & & & & & & & & & o \\
\hline 3 & N.A. & N.A. & N.A. & & & & & & & & 0 \\
\hline 4 & N.A. & N.A. & N.A. & N.A. & & & & & & & 2.07 \\
\hline 5 & N.A. & N.A. & N.A. & N.A. & N.A. & & & & & & 2.07 \\
\hline 6 & N.A. & N.A. & N.A. & N.A. & N.A. & 1.0000 & & & & & 10.42 \\
\hline 7 & N.A. & N.A. & N.A. & N.A. & N.A. & 0.3143 & 1.0000 & & & & 25.00 \\
\hline $\mathbf{B}$ & N.A. & N.A. & N.A. & N.A. & N.A. & N.A. & N.A. & 1.0000 & & & 4.17 \\
\hline 9 & N.A. & N.A. & N.A. & N.A. & N.A. & 0.2421 & 0.7702 & N.A. & 1.0000 & & 16.67 \\
\hline 10 & N.A. & N.A. & N.A. & N.A. & N.A. & -0.3201 & 0.0457 & N.A. & -0.2465 & 1.0000 & 39.60 \\
\hline
\end{tabular}

1 - Lumber t Hood 2 - Other Durable coods 3 - Food Products i = Other Non-Durable Goods

5 - Construction 6 - Tranaportation. Comnunications \& Utilitieg 7 - Trade 8 - Finance.

Insurance, Real Egtate 9 - Services 10 - Government N.A. - Hot Avallable

- Porcent of total Employment 